\title{
Chronic Stress Induces Maladaptive Behaviors by Activating Corticotropin-Releasing Hormone Signaling in the Mouse Oval Bed Nucleus of the Stria Terminalis
}

\author{
Pu Hu, ${ }^{1}$ Ji Liu, ${ }^{2}$ Isabella Maita, ${ }^{1}$ Christopher Kwok, ${ }^{1}$ Edward Gu, ${ }^{1}$ @Mark M. Gergues, ${ }^{1}$ Frederric Kelada, ${ }^{1}$ Mimi Phan, ${ }^{1}$ \\ Jiang-Ning Zhou, ${ }^{3}$ Dick F. Swaab, ${ }^{4}$ ZZhiping P. Pang, ${ }^{2}$ Paul J. Lucassen, ${ }^{5}{ }^{\circ}$ Troy A. Roepke, ${ }^{6}$ and $\odot$ Benjamin A. Samuels ${ }^{1}$ \\ ${ }^{1}$ Department of Psychology, Rutgers University, Piscataway, New Jersey 08854, ${ }^{2}$ Department of Neuroscience and Cell Biology, Rutgers Robert Wood \\ Johnson Medical School, New Brunswick, New Jersey 08901, ${ }^{3}$ CAS Key Laboratory of Brain Function and Disease, School of Life Science, University of \\ Science and Technology of China, Hefei, 230027, China, ${ }^{4}$ Department of Neuropsychiatric Disorders, Netherlands Institute for Neuroscience, An Institute of \\ the Royal Netherlands Academy of Arts and Sciences, Meibergdreef, 1105 BA Amsterdam, The Netherlands, ${ }^{5}$ Brain Plasticity Group, Swammerdam \\ Institute for Life Sciences, Center for Neuroscience, University of Amsterdam, 1098 XH Amsterdam, The Netherlands, and ${ }^{6}$ Department of Animal Sciences, \\ School of Environmental and Biological Sciences, Rutgers University, New Brunswick, New Jersey 08901
}

The bed nucleus of the stria terminalis (BNST) is a forebrain region highly responsive to stress that expresses corticotropin-releasing hormone (CRH) and is implicated in mood disorders, such as anxiety. However, the exact mechanism by which chronic stress induces CRH-mediated dysfunction in BNST and maladaptive behaviors remains unclear. Here, we first confirmed that selective acute optogenetic activation of the oval nucleus BNST (ovBNST) increases maladaptive avoidance behaviors in male mice. Next, we found that a 6 week chronic variable mild stress (CVMS) paradigm resulted in maladaptive behaviors and increased cellular excitability of ovBNST CRH neurons by potentiating $\mathrm{mEPSC}$ amplitude, altering the resting membrane potential, and diminishing $\mathrm{M}$-currents (a voltage-gated $\mathrm{K}^{+}$ current that stabilizes membrane potential) in ex vivo slices. CVMS also increased $\mathrm{c}$-fos ${ }^{+}$cells in ovBNST following handling. We next investigated potential molecular mechanism underlying the electrophysiological effects and observed that CVMS increased $\mathrm{CRH}^{+}$and pituitary adenylate cyclase-activating polypeptide ${ }^{+}$(PACAP; a CRH upstream regulator) cells but decreased striatal-enriched protein tyrosine phosphatase ${ }^{+}$(a STEP CRH inhibitor) cells in ovBNST. Interestingly, the electrophysiological effects of CVMS were reversed by CRHR1-selective antagonist R121919 application. CVMS also activated protein kinase A (PKA) in BNST, and chronic infusion of the PKA-selective antagonist H89 into ovBNST reversed the effects of CVMS. Coadministration of the PKA agonist forskolin prevented the beneficial effects of R121919. Finally, CVMS induced an increase in surface expression of phosphorylated GluR1 (S845) in BNST. Collectively, these findings highlight a novel and indispensable stress-induced role for PKA-dependent CRHR1 signaling in activating BNST CRH neurons and mediating maladaptive behaviors.

Key words: anxiety; bed nucleus of stria terminalis; chronic stress; corticotropin releasing hormone

Significance Statement

Chronic stress and acute activation of oval bed nucleus of the stria terminalis (ovBNST) induces maladaptive behaviors in rodents. However, the precise molecular and electrophysiological mechanisms underlying these effects remain unclear. Here, we demonstrate that chronic variable mild stress activates corticotropin-releasing hormone (CRH)-associated stress signaling and CRH neurons in ovBNST by potentiating mEPSC amplitude and decreasing M-current in male mice. These electrophysiological alterations and maladaptive behaviors were mediated by BNST protein kinase A-dependent CRHR1 signaling. Our results thus highlight the importance of BNST CRH dysfunction in chronic stress-induced disorders.

\section{Introduction}

Chronic stress exposure triggers maladaptive behavioral responses and can induce mood disorders, such as anxiety (de Kloet

Received Oct. 9, 2019; revised Jan. 16, 2020; accepted Jan. 16, 2020.

Author contributions: P.H., T.A.R., and B.A.S. designed research; P.H., J.L., I.M., C.K., E.G., M.M.G., F.K., and M.P. performed research; P.H., J.-N.Z., T.A.R., and B.A.S. analyzed data; P.H. wrote the first draft of the paper; J.-N.Z., et al., 2005; Joëls and Baram, 2009; Lucassen et al., 2014). The limbic forebrain structure bed nucleus of the stria terminalis

D.F.S., Z.P.P., P.J.L., T.A.R., and B.A.S. edited the paper; D.F.S., Z.P.P., and P.J.L. contributed unpublished reagents/ analytic tools.

This work was supported by National Institute of Mental Health Grant R01 MH112861 to B.A.S., NW0 and Alzheimer Nederland and the Urban Mental Health Program of the University of Amsterdam to P.J.L., National 
(BNST) is critical for mediating the neuroendocrine stress response (Choi et al., 2007; Vranjkovic et al., 2014) and potential threat regulation (Clauss et al., 2019; Goode et al., 2019). BNST receives information from the limbic system and projects to neuroendocrine and autonomic neural systems located in brainstem and hypothalamus regions that mediate the hypothalamicpituitary-adrenal (HPA) stress response (Herman and Cullinan, 1997; Ch'ng et al., 2018). In rodents, stimulating BNST elicits maladaptive avoidance responses (Walker et al., 2003), whereas BNST inactivation elicits exploration (Hammack et al., 2004). Importantly, BNST also plays a pivotal role in the development and progression of drug and alcohol abuse disorders (Silberman and Winder, 2013).

Stress induces corticotropin-releasing hormone (CRH or CRF release), abundantly expressed in the hypothalamic paraventricular nucleus neurons responsible for HPA regulation (Kageyama and Suda, 2009) and cortisol release (Rivier and Vale, 1983). Interestingly, CRH is also highly expressed in BNST (Pomrenze et al., 2015; Sanford et al., 2017), especially in the oval nucleus (ovBNST) of the anterodorsolateral BNST (BNSTadl) (Ju and Swanson, 1989; Daniel and Rainnie, 2016). Indeed, the highest concentration of CRH neurons in the brain is located in ovBNST (Cummings et al., 1983; Morin et al., 1999; Daniel and Rainnie, 2016), a region thought to be a master controller of BNST outflow (Ch'ng et al., 2018). Optogenetic inhibition of ovBNST decreases, whereas stimulation promotes, maladaptive avoidance behaviors in mice (Kim et al., 2013). Notably, BNST orchestrates stress responses in a CRH-dependent fashion (Silberman and Winder, 2013; Silberman et al., 2013; Pomrenze et al., 2019), and CRH neurons in BNSTadl mediate maladaptive behavioral effects (Daniel and Rainnie, 2016; Gungor and Paré, 2016). Both CRH injections and CRH overexpression in BNST increase maladaptive avoidance behaviors (Sahuque et al., 2006; Sink et al., 2013). Thus, BNST CRH dysfunction contributes to stress-related maladaptive behaviors (Silberman and Winder, 2013) and possibly mood disorders (Walker et al., 2009; Sink et al., 2013).

Although BNST CRH-mediated mechanisms play a pivotal role in stress-induced maladaptive behaviors, the precise mechanisms underlying how chronic stress induces BNST CRH neuronal dysfunction and subsequent maladaptive behaviors remain elusive. An improved mechanistic understanding of how stress affects BNST CRH signaling will assist development of more effective therapeutics to treat stress-related disorders. Here we test the hypothesis that chronic stress upregulates BNST CRH neuronal excitability and delineate the $\mathrm{CRH}$ receptor-mediated mechanisms underlying BNST-mediated stress-induced maladaptive behaviors. Interestingly, Kim et al. (2013) demonstrated that ovBNST activation increases maladaptive avoidance behaviors. Similar to their study, we first injected Cre-inducible ChR2 virus into ovBNST of male mice where Cre expression was restricted to ovBNST. As expected, direct optogenetic activation of ovBNST acutely increased maladaptive avoidance behaviors. Next, we used a chronic variable mild stress (CVMS; also known as chronic unpredictable mild stress) paradigm in male mice to study how chronic stress elicits BNST CRH neuronal dysfunction

\footnotetext{
Institutes of Health Grant R21 ES027119 to T.A.R., and NIAA Grant R01 AA023797 to Z.P.P. We thank Prof. Tracey J. Shors, Christine Yohn, Kaci Shu, Bren Wu, Ashley Huang, Nicole Jallali, Andrew Dieterich, Ali Yasrebi, and Hannah Wang for helpful discussions and/or technical assistance.

The authors declare no competing financial interests.

Correspondence should be addressed to Benjamin A. Samuels at ben.samuels@rutgers.edu.

https://doi.org/10.1523/JNEUROSCI.2410-19.2020

Copyright $\odot 2020$ the authors
}

and maladaptive behaviors. To this end, we first assessed effects of CVMS on ovBNST neuronal excitability by examining resting membrane potential, mEPSCs, and M-currents (a voltagedependent noninactivating $\mathrm{K}^{+}$current that stabilizes cellular membrane potential). Second, we investigated whether CVMS alters expression of CRH signaling components (including CRH upstream stress regulator pituitary adenylate cyclase-activating polypeptide; PACAP) (Stroth et al., 2011; Lezak et al., 2014) and the CRH inhibitor striatal-enriched protein tyrosine phosphatase (STEP) (Dabrowska et al., 2013) in BNST. Finally, we delineated the role of BNST CRHR1 in mediating CVMS-induced maladaptive behaviors by local pharmacological administration of a CRHR1-selective antagonist. Our results indicate that activation of protein kinase A (PKA)-dependent CRHR1 signaling increases ovBNST CRH neuronal excitability and mediates CVMSinduced maladaptive behaviors.

\section{Materials and Methods}

Mice. All procedures were in accordance with National Institutes of Health standards and approved by either the Rutgers or the University of Science and Technology Institutional Animal Care and Use Committee. All mice used (except for optogenetics) were adult male C57BL/6J mice ( 6 weeks age upon arrival and were allowed for habituation for 1-2 weeks before experiment starts) purchased from The Jackson Laboratory. For optogenetics, dopamine receptor D1a (Drdla)-Cre (GENSAT line EY266) transgenic mice with Cre expression restricted to the ovBNST (Kim et al., 2013) were generated via in house breeding. Except for the CVMS procedure, all mice were maintained in a temperature-controlled room $\left(22^{\circ} \mathrm{C}\right)$ and under a $12 / 12 \mathrm{~h}$ light/dark cycle with food and water provided ad libitum.

CVMS. CVMS was performed as described previously (Surget et al., 2008; Sterrenburg et al., 2011) and persisted for 6 weeks. Variable mild stressors used were as follows: daily bedding alterations (repeated sawdust changes, removal of sawdust, damp sawdust, substitution of sawdust with $21^{\circ} \mathrm{C}$ water), cage-tilting $\left(45^{\circ}\right.$ angle), predator sounds ( $15 \mathrm{~min}$ ), cage shift (placed into the empty cage of another male), alterations of the light/dark cycle, lights off for $180 \mathrm{~min}$, and overnight food/water deprivation (Surget et al., 2008; Sterrenburg et al., 2011). First, 50 mice were randomly assigned to nonstress (Control) $(n=25)$ or CVMS groups $(n=25)$. Among them, 20 mice were used for behavior $(n=10$ per group) and subsequent immunohistochemistry (IHC; randomly selected $n=6$ per group), 12 for electrophysiology ( $n=6$ per group), and 18 for plasma corticosterone (CORT) measurements and real-time quantitative PCR analysis (qPCR) ( $n=7-9$ per group). Second, for electrophysiological recordings testing the effects of R121919, H89, Rp-adenosine $3^{\prime}, 5^{\prime}$-cyclic monophosphorothioate triethylammonium salt (Rp-cAMPS), or R121919 together with forskolin in ex vivo slices a distinct cohort of control $(n=7)$ and CVMS $(n=8)$ groups were used. Third, for cannula drug infusions and subsequent behavioral tests, additional cohorts containing Control, Control + R121919, Control + H89, CVMS + $\mathrm{R} 121919, \mathrm{CVMS}+\mathrm{H} 89$, and CVMS + R121919 + forskolin groups $(n=$ 7 per group) were used.

Behavior tests. Behavior was conducted between 8:00 A.M. and 12:00 noon. Mice were allowed overnight adaptation to the behavioral rooms.

Sucrose preference. Animals were first trained to drink 1\% (w/v) sucrose solution for a $48 \mathrm{~h}$ adaptation period (Samuels et al., 2017). At 8:30 A.M. on testing day, they were given free access to two bottles (each containing normal water and sucrose solution, respectively). To avoid left/right preference, the left-right placement order of water versus sucrose bottle was alternated for each mouse during the middle time point of the testing period. Bottles were weighed at the beginning and end of the testing $24 \mathrm{~h}$ later. The percentage of sucrose solution relative to the total liquid consumed during $24 \mathrm{~h}$ was then determined as a measure for anhedonia.

Elevated Plus Maze (EPM). The EPM test evaluates avoidance behavior (Samuels et al., 2015). Mice were placed in the central arena of a black plus-shaped maze, facing an open arm, and were left to explore for 10 
min. The duration and frequency of which open or closed arms were explored was analyzed by video camera and processed by EthoVision (Noldus).

Open Field (OF). OF test analyzes exploratory activity (Samuels et al., 2017) and is often used to evaluate avoidance behavior together with the EPM test. The apparatus consists of a black floor area $(40.5 \mathrm{~cm} \times 40.5$ $\mathrm{cm})$, with a $37.5 \mathrm{~cm}$ high transparent wall. Mice were placed in the center of apparatus (middle square) and monitored for $30 \mathrm{~min}$. Data were collected and processed with EthoVision (Noldus). Distance, duration of time that mice spent in the center, and the frequency of mice entry into the center area was documented and analyzed.

Novelty Suppressed Feeding (NSF) Test. The NSF test elicits competing motivations between the drive to eat and the fear of venturing into the center of a brightly lit arena, and is often used to evaluate avoidance (Samuels et al., 2015). Mice were first food-deprived for $18 \mathrm{~h}$ (starting at 2:00 P.M. the previous day) and then placed into holding cages at 8:00 A.M. on the testing day. After $60 \mathrm{~min}$, the mice were placed into a novel, brightly lit (1200 lux) arena ( 16 inches $\times 20$ inches) with a pellet of chow placed in the center of the arena affixed to a circular platform of white filter paper $(10 \mathrm{~cm})$. The time taken for the mice to bite the food pellet for the first time was recorded as the latency to eat, at which point the pellet was immediately removed from the arena.

Basal plasma corticosterone concentration assay. Following CVMS, 18 mice ( $n=9$ from the Control and CVMS group) were quickly decapitated following euthasol administration ( $150 \mathrm{mg} / \mathrm{kg}$ i.p.; Henry Schein). Trunk blood samples were collected and plasma was isolated and then stored at $-80^{\circ} \mathrm{C}$ for CORT measurements using an enzyme-linked immunoassay kit (K014-H1; DetectX).

Real-time $q R T-P C R$ analysis. After euthasol administration, brains were isolated, and $160-\mu \mathrm{m}$-thick sections containing BNST were collected (AP $0.10 \mathrm{~mm}$ to $-0.46 \mathrm{~mm}$ ). The BNSTadl was punched and stored at $-80^{\circ} \mathrm{C}$. Total RNA and protein from BNSTadl were extracted using the RNA/Protein purification plus kit (48200; Norgen Biotek) and stored at $-80^{\circ} \mathrm{C}$. mRNA expression was analyzed with eukaryotic $18 \mathrm{~S}$ rRNA endogenous control (Taqman VICTM probe; Invitrogen) primers for PCR amplification. cDNA was synthesized using SuperScript IV VILO Master Mix (with ezDNase enzyme, 11766050; Invitrogen) as the reverse transcriptase. qPCR was performed with Taqman Fast Advanced Master Mix (4444557; Thermo Fisher Scientific), control probe and each target gene FAM Taqman Probe. The relative amount of target gene was calculated using the $2^{-\Delta \Delta \mathrm{Ct}}$ method (Livak and Schmittgen, 2001).

Western blot. Protein samples from the BNSTadl of Control versus CVMS mice were probed with anti-phospho-PKA C (Thr197) (rabbit, poly; 1:1000; 4781; Cell Signaling Technology), anti-PKA (C- $\alpha$ ) (rabbit, poly; 1:1000; 4782; Cell Signaling Technology), or anti-STEP (mouse, mono; 1:1000; 23E5; Cell Signaling Technology), with GAPDH as internal control (rabbit; 1:10,000; G9545; Sigma Millipore); and then HRP-conjugated goat-anti-rabbit and goat-anti-mouse IgG secondary antibodies (1:10,000; 31460, Thermo Fisher Scientific), respectively, operated on an iBind Flex Western device (Thermo Fisher Scientific). Immunoblot signals were then detected with an ECL chemiluminescence system (SuperSignal West Pico Chemiluminescence Substrate, Pierce) and imaged with myECL imager (Thermo Fisher Scientific). Immunoblots were quantified, and density was calculated using ImageJ software (Wayne Rasband, National Institute of Mental Health). Results were expressed as percentage of GAPDH.

Brain tissue, immunohistochemistry, and image acquisition. Following behavioral analysis, 12 mice ( $n=6$ for each CVMS or Control group) were administered euthasol and perfused transcardially with saline and $4 \%$ PFA. Brains were cryoprotected in 30\% sucrose, and then $40-\mu \mathrm{m}$ thick sections were cut on a cryostat. Immunohistochemistry was performed using standard procedures (Hu et al., 2013) with anti-CRH (rabbit, ab8901, 1:400; Abcam) (García-Moreno et al., 2010), anti-c-fos (rabbit, 9F6, 1:800; Cell Signaling Technology), anti-PACAP (rabbit, ab216627, 1:700; Abcam), or anti-STEP (mouse, 23E5, 1:500; Novus Biologicals). For CRH staining, we performed intracerebral ventricular administration of colchicine (Sigma Millipore; C9754) before perfusion; $1 \mu \mathrm{l}$ colchicine $(10 \mu \mathrm{g} / \mu \mathrm{l}$; dissolved in $0.9 \%$ saline) was injected into the lateral ventricle of mice (anteroposterior $-0.5 \mathrm{~mm}$; mediolateral \pm 1.0 -
$1.1 \mathrm{~mm}$; dorsoventral -2.5 mm) (DeVos and Miller, 2013) through an injection cannula (connected to a syringe with UltraMicroPump, UMP3; World Precision Instruments) and SYS-Micro4 Controller (UMC4; World Precision Instruments) at a speed of $100 \mathrm{nl} / \mathrm{min}$. The needle was kept in place for $5 \mathrm{~min}$ after injection. Mice were then perfused after $48 \mathrm{~h}$. For PACAP and STEP staining, mounted sections were first subjected to antigen-retrieval consisting of being heated in a citrate buffer ( $\mathrm{pH} 6.0$; Sigma Millipore) for $2 \mathrm{~min}$. Signal amplification was performed with biotinylated goat-anti-rabbit (A27035, 1:10,000; Invitrogen) or biotinylated goat-anti-mouse (A28176, 1:10,000; Invitrogen) IgG superclonal secondary antibodies, followed by avidin-biotin complex (1:50; PK6100, Vector Laboratories). Chromogen development was performed with DAB (1:50; SK-4100, Vector Laboratories; 0.01\% $\mathrm{H}_{2} \mathrm{O}_{2}$ ).

Photographs were taken using an Invitrogen EVOS FL Auto 1 Cell Imaging System (Invitrogen). Numbers of $\mathrm{c}^{-} \mathrm{fos}^{+}, \mathrm{CRH}^{+}, \mathrm{PACAP}^{+}$, and STEP ${ }^{+}$immunopositive cells expressed in oval nucleus (ovBNST) were manually counted bilaterally at a $20 \times$ magnification by an investigator blind to the experimental conditions.

Electrophysiological recordings (M-current and mEPSC) of ovBNST CRH neurons. Electrophysiology was performed as described previously (Roepke et al., 2011; Hu et al., 2016). Mice were quickly decapitated between 10:00 A.M. and 11:00 A.M. In total, 6 control mice and 6 CVMS mice were used. All the drugs used in the patch-clamp recordings were purchased from Tocris Bioscience unless otherwise specified. Standard whole-cell voltage-clamp patch recording procedures were performed. Pipettes made of borosilicate glass were pulled with a PC-10 Puller (Narishige).

After death, the brain was rapidly removed from the skull, and a block containing the BNST was immediately dissected and submerged in cold $\left(4^{\circ} \mathrm{C}\right)$ oxygenated $\left(95 \% \mathrm{O}_{2}, 5 \% \mathrm{CO}_{2}\right)$ high-sucrose aCSF containing the following (in $\mathrm{mM}$ ): 208 sucrose, $2 \mathrm{KCl}, 26 \mathrm{NaHCO}_{3}, 10$ glucose, 1.25 $\mathrm{NaH}_{2} \mathrm{PO}_{4}, 2 \mathrm{MgSO}_{4} 1 \mathrm{MgCl}_{2}, 10$ HEPES, pH 7.3, 300 mOsm. Coronal slices $(250 \mu \mathrm{m})$ were cut on a vibratome at $4^{\circ} \mathrm{C}$. The slices were then transferred to an auxiliary chamber in which they were kept at room temperature $\left(25^{\circ} \mathrm{C}\right)$ (recovery for $1-2 \mathrm{~h}$ ) in aCSF consisting of the following (in mM): $124 \mathrm{NaCl}, 5 \mathrm{KCl}, 2.6 \mathrm{NaH}_{2} \mathrm{PO}_{4}, 2 \mathrm{MgCl}_{2}, 2 \mathrm{CaCl}_{2}, 26$ $\mathrm{NaHCO}_{3}, 10$ glucose, $\mathrm{pH} 7.3,310$ mOsm until recording. A single slice was transferred to the recording chamber mounted on an Olympus BX51W1 upright fluorescent microscope. The slice was then continually perfused with warm $\left(35^{\circ} \mathrm{C}\right)$ oxygenated aCSF at $1.5 \mathrm{ml} / \mathrm{min}$. Targeted neurons were viewed with an Olympus $40 \times$ water-immersion lens.

Standard whole-cell voltage-clamp patch recording procedures were performed in BNST slices (Roepke et al., 2011; Hu et al., 2016). All recordings were restricted to ovBNST (anatomy shown in Fig. 2A; with bregma $-0.26 \mathrm{~mm}$ in Swanson Brain Atlas, interaural $8.74 \mathrm{~mm}$ ) (Krawczyk et al., 2011; Daniel and Rainnie, 2016). Recordings of ovBNST $\mathrm{CRH}$-positive neurons were based on both: (1) anatomical criteria (located within oval nucleus region of BNSTadl [dorsal to the point halfway between the tip of lateral ventricle and the top of the anterior commissure]); and (2) post hoc immunohistochemistry staining identification: confirmation of $\mathrm{CRH}^{+}$cells was done by labeling recorded cells with AlexaFluor-633 (green; Invitrogen) dye filled in the internal solution, followed by post hoc immunohistochemical analysis with CRH antibody (AlexaFluor-594, red) (Hu et al., 2016). Sections were fixed with 4\% PFA (Sigma Millipore) overnight at $4^{\circ} \mathrm{C}$. Immunohistochemistry was performed with anti-CRH primary antibody (rabbit, 1:1000; Abcam) and goat-anti-rabbit AlexaFluor-594 secondary antibody (1:1000; Invitrogen). Only neurons that were validated as $\mathrm{CRH}$-immunopositive and qualified for the above criteria were included in the final analyses. A typical example of CRH neuron in ovBNST is shown in yellow color (Fig. $2 L$ ) designated by an arrow.

An Axopatch 700B amplifier, Digidata 1322A Data Acquisition System, and pCLAMP software (version 10.2; Molecular Devices) were used for data acquisition and analysis. Input resistance (IR), series resistance, and membrane capacitance were all monitored throughout the experiments. Only cells with stable series resistance $(<30 \mathrm{M} \Omega ;<20 \%$ change over the course of the recording) and suitable IR $(>500 \mathrm{M} \Omega)$ were used for analysis. To record $\mathrm{M}$-currents, pipettes (3-5 $\mathrm{M} \Omega$ resistance) were filled with internal solution containing the following (in $\mathrm{mm}$ ): $10 \mathrm{NaCl}$, 
128 K-gluconate, $1 \mathrm{MgCl}_{2}$, 10 HEPES, 1 ATP, 1.1 EGTA, 0.25 GTP; pH 7.3, $300 \mathrm{mOsm} ; 1 \mu \mathrm{M}$ TTX was included in the recording aCSF to block $\mathrm{Na}^{+}$-spike-dependent synaptic inputs. Under the voltage clamp, a standard deactivation protocol (see Fig. $2 \mathrm{H}$ ) was used to measure $\mathrm{K}^{+}$currents current-voltage $(I-V)$ plots elicited during $500 \mathrm{~ms}$ voltage steps from -30 to $-75 \mathrm{mV}$ in $5 \mathrm{mV}$ increments after a $300 \mathrm{~ms}$ prepulse to -20 $\mathrm{mV}$ from a holding potential of $-60 \mathrm{mV}$. From this protocol, the IR was determined from the slope of the $I-V$ plot in the range between -60 and $-80 \mathrm{mV}$. The amplitude of M-current relaxation or deactivation was measured as the difference between the initial $(<10 \mathrm{~ms})$ and sustained current $(>475 \mathrm{~ms}$ ) of the current trace under control condition (TTX only; $1 \mu \mathrm{M} ; 5 \mathrm{~min})$. After baseline recording ( $\sim \mathrm{min})$, deactivation protocol was repeated twice and averaged for analysis.

To study excitatory synaptic transmission, pharmacologically isolated mEPSCs were recorded as described previously (Hu et al., 2016). Picrotoxin $(50 \mu \mathrm{M})$ was added to block inhibitory synaptic transmission mediated by GABAA receptor, and meanwhile D-APV $(50 \mu \mathrm{M})$ was added to block currents mediated by NMDARs. In addition, TTX $(1 \mu \mathrm{M})$ was included to block action potential. Internal solution contained the following (in mM): $40 \mathrm{CsCl}$, $90 \mathrm{~K}-G l u c o n a t e, 10$ HEPES, 0.05 EGTA, 1.8 $\mathrm{NaCl}, 3.5 \mathrm{KCl}, 1.7 \mathrm{MgCl}_{2}$, $2 \mathrm{Mg}$-ATP, $0.4 \mathrm{Na} 4-\mathrm{GTP}, 10$ phosphocreatine, and $5 \mathrm{~N}$-2,6-dimethylphenylcarbamoylmethy)-triethylammonium (QX-314), and was adjusted to pH 7.3, 280-290 mOsm (Liu et al., 2017). After a stable baseline recording of $\sim 5 \mathrm{~min}$ period, mEPSC was continuously recorded for $\sim 10 \mathrm{~min}$. The mEPSC properties recorded during the last $5 \mathrm{~min}$ period were compared.

To test the possibility of CRHR1- and PKA-mediated effects of CVMS on the electrophysiological properties, coronal BNST slices from $n=8$ CVMS or $n=7$ control mice were incubated with $1 \mu \mathrm{M}$ CRHR1-selective antagonist R121919 (Tocris Bioscience) (Heinrichs et al., 2002; Gutman et al., 2003; Chen et al., 2004; Herman et al., 2016), or $10 \mu \mathrm{M}$ PKAselective inhibitor H89 (Tocris Bioscience) (Qiu et al., 2003; Hu et al., 2016) or $1 \mu \mathrm{M}$ R121919 together with $50 \mu \mathrm{M}$ PKA-selective agonist forskolin (Sigma Millipore) (Sokolova et al., 2006) in the aCSF for at least 30 min ahead at room temperature before transferred to the recording chamber for current recording; $100 \mu \mathrm{M}$ nonhydrolyzable cAMP analog Rp-cAMPS (Sigma Millipore) (Lochner and Moolman, 2006; Yi et al., 2013) was applied by intracellular dialysis to block PKA activation through the patch pipette solution $5 \mathrm{~min}$ before recording to occlude the activation of intracellular PKA.

To assess the effects of CRH on ovBNST neuron electrophysiological properties, coronal BNST slices from control mice $(n=5)$ were directly bath perfused with $300 \mathrm{~nm} \mathrm{CRH} \mathrm{(MedChemExpress)} \mathrm{(Kash} \mathrm{et} \mathrm{al.,} \mathrm{2008).}$ For M-current recording, CRH was perfused for $10 \mathrm{~min}$ immediately following a $5 \mathrm{~min}$ baseline recording with $1 \mu \mathrm{M}$ TTX. For mEPSC recording, $\mathrm{CRH}$ was perfused for $\sim 10 \mathrm{~min}$ following a stable $5 \mathrm{~min}$ baseline measurement.

Local cannula drug infusion into ovBNST. CVMS mice ( $n=7$ or 8 per group) were bilaterally implanted with a guide cannula (C315G/SPC, Plastics One) directly into ovBNST (bregma AP $0.2 \mathrm{~mm}$, ML $1.0 \mathrm{~mm}$, DV $-4.1 \mathrm{~mm}$ ) (example picture shown in Figs. $4 B, 6 E$ ). A Hamilton syringe (HSYR-1 Syringe 86200, P1 Technologies) was connected with a segment of PE tubing (C313CT/PKG, Plastics One) for drug infusion. The CRHR1-selective antagonist R121919 ( $1 \mu \mathrm{g}$ in $0.5 \mu \mathrm{l}$ saline) (Pomrenze et al., 2019), PKA-selective antagonist H89 (25 nM dissolved in $0.5 \mu \mathrm{l}$ saline) (Wei et al., 2002), or R121919 (1 $\mu \mathrm{g})$ together with PKA-selective agonist forskolin (120 nм; dissolved in $0.5 \mu$ l saline) (Wei et al., 2002) were continuously infused at a rate of $0.05 \mu \mathrm{l} / \mathrm{min}$ into the ovBNST for $7 \mathrm{~d}$. Daily CVMS exposure was continuously present during the whole drug infusion period.

Adeno-associated virus (AAV) injection and fiberoptic implantation. To ensure ovBNST regional selectivity, male Drd1a-Cre transgenic mice (8-10 weeks of age) in which Cre expression is restricted to the ovBNST were bilaterally injected with at least $0.35 \mu$ l of either AAV5-EF1 $\alpha$-DIOChR2 (H134R)-eYFP (ChR2:ovBNST; ChR2) or AAV5-EF1 $\alpha$-DIOeYFP virus (eYFP:ovBNST; Control) (University of North Carolina at Chapel Hill, NC; titer $2 \times 10^{12}$ particles $/ \mathrm{ml}$ ) into ovBNST (AP $0.2 \mathrm{~mm}$, ML $1.0 \mathrm{~mm}$, DV $-4.1 \mathrm{~mm}$; relative to bregma) (Kim et al., 2013), using a Nanoject III Programmable Nanoliter Injector (Drummond Scien- tific). The injection rate was $2 \mathrm{nl} / \mathrm{s}$ and the needle remained in place for an additional 5-7 min before a slow withdrawal to avoid upward flow and to allow stable penetration of virus into brain tissue. Next, a prepolished fiberoptic cable (FT200UMT; $200 \mu \mathrm{m}$ core; Thorlabs) connected through a ceramic ferrule (CFLC230-10; diameter $1.25 \mathrm{~mm}$, length 6.4 $\mathrm{mm}$, Thorlabs; bore size $230 \mu \mathrm{m}$ ) was slowly implanted directly above the ovBNST on each side. Adhesive glue was first applied surrounding the ferrule, and then dental cement was added to secure the ferrule to the skull. Finally, the incision was closed using tissue adhesive. Mice were put into a warm cage to facilitate recovery from anesthesia for at least $30 \mathrm{~min}$ before they were placed back into the colony room. Mice were then allowed to recover from surgery for at least 3 weeks before behavioral testing.

Light delivery and optogenetic-controlled behavioral tests. For the optogenetic behavioral study, $n=8$ control and $n=8 \mathrm{ChR} 2$ mice were used. Both groups were subjected to $3-5 \mathrm{~mW}$ of blue light $\left(95-159 \mathrm{~mW} / \mathrm{mm}^{2}\right.$ ) generated by a $473 \mathrm{~nm}$ DPSS laser system (MBL-III 473; Opto Engine) and bilaterally delivered (Kim et al., 2013) through a fiberoptic patch cord made from prepolished fiberoptic cable (FT200UMT; $200 \mu \mathrm{m}$ core; Thorlabs) connected through the ceramic ferrule and a stainless-steel ferrule multimode connector (F12774, $230 \mu \mathrm{m}$; Fiber Instrument Sales). Blue laser output was controlled using a pulse generator (Master-8; A.M.P.I.) to deliver $5 \mathrm{~ms}$ light pulse trains at $10 \mathrm{~Hz}$ frequency. For the EPM and OF tests, each light OFF-ON-OFF session consisted of either 5 $\min (\mathrm{EPM})$ or $10 \mathrm{~min}(\mathrm{OF})$ epochs. The laser OFF or ON was precisely controlled manually by the investigator through controlled by a Master 8 pulse generator (A.M.P.I.).

Quantification of surface expression of phosphorylated AMPAR GluR1 ( $p$ GluR1-S845). To compare the surface expression of phosphorylated GluR1 (AMPAR subunit 1 at Serine 845), a brain slice surface biotinylation method (Gabriel et al., 2014) was used to isolate surface pGluR1SS845. Coronal BNST slices ( $300 \mu \mathrm{m}$ thickness) from $n=5$ Control and $n=5$ CVMS mice were freshly cut with vibrating microtome and allowed to recover at $31^{\circ} \mathrm{C}$ in oxygenated aCSF (composed of $125 \mathrm{~mm} \mathrm{NaCl}, 2.5$ mм KCl, $1.2 \mathrm{~mm} \mathrm{NaH}_{2} \mathrm{PO}_{4}, 1.2 \mathrm{~mm} \mathrm{MgCl}_{2}, 2.4 \mathrm{~mm} \mathrm{CaCl}_{2}, 26 \mathrm{~mm}$ $\mathrm{NaHCO}_{3}$, and $11 \mathrm{~mm}$ glucose) for $40 \mathrm{~min}$. Then slices were incubated with $0.75 \mathrm{ml}$ sulfo-N-hydroxysuccinyl-SS-biotin (sulfo-NHS-SS-bioton; Pierce Chemical) on ice for $45 \mathrm{~min}$. After being washed with ice-cold aCSF, slices were then incubated on ice for $10 \mathrm{~min}$ with ice-cold aCSF. Then slices were then washed 3 times with ice-cold slice quench buffer (aCSF supplemented with $100 \mathrm{~mm}$ glycine) and incubated with $0.75 \mathrm{ml}$ slice quench buffer on ice for 25 min to quench free sulfo-NHS-SSbiotin. Then slices were transferred to microcentrifuge tubes to be gently pelleted by centrifuge at $200 \times g$ for $1 \mathrm{~min}$. After adding $400 \mu \mathrm{l}$ cold RIPA/PI (RIPA supplemented with $1 \mu \mathrm{M}$ leupeptin, $1 \mu \mathrm{M}$ pepstatin, $1 \mu \mathrm{M}$ aprotinin, and $1 \mathrm{~mm}$ PMSF), tissue was broken up by pipetting through P200 pipette. Then dissociated slice/RIPA was transferred to fresh tube, then incubated for $30 \mathrm{~min}$ at $4^{\circ} \mathrm{C}$, and rotated to complete lysis. After cellular debris were pelleted by centrifuging at $18,000 \times g 15 \mathrm{~min}$ at $4^{\circ} \mathrm{C}$, lysate protein was prepared for biotinylation with streptavidin-agarose beads (Thermo Fisher Scientific) according to the protocol (Gabriel et al., 2014).

Cell lysates were distributed to the tubes containing agarose beads (Thermo Fisher Scientific); then additional RIPA/PI were added to bring to samples to a $200 \mu \mathrm{l}$ volume. Then tubes were rotated and mixed overnight at $4^{\circ} \mathrm{C}$. Equivalent total lysate volume was dispensed in separated tubes for each sample. Then an equal volume of $2 \times$ SDS-PAGE sample buffer was added, and samples were incubated at $4^{\circ} \mathrm{C}$ in parallel with bead samples until samples were analyzed.

After pelleting beads by centrifuging at $18,000 \times g$ for $2 \mathrm{~min}$, supernatant was aspirated and beads were washed with $0.75 \mathrm{ml}$ RIPA. Then after the final wash, the RIPA was aspirated and biotinylated proteins were eluted from streptavidin beads by reducing the disulfide linkage with 25 $\mu \mathrm{l} 2 \times$ SDS-PAGE sample buffer and rotating for $30 \mathrm{~min}$. The final samples were stored frozen. Total lysate samples were thawed and rotated in parallel with bead samples for $30 \mathrm{~min}$ at room temperature. Then proteins were separated by SDS-PAGE gels and identified by immunoblotting with anti-phospho-S845 GluR1 antibody (ab76321; rabbit, 1:1000; Abcam). 
A

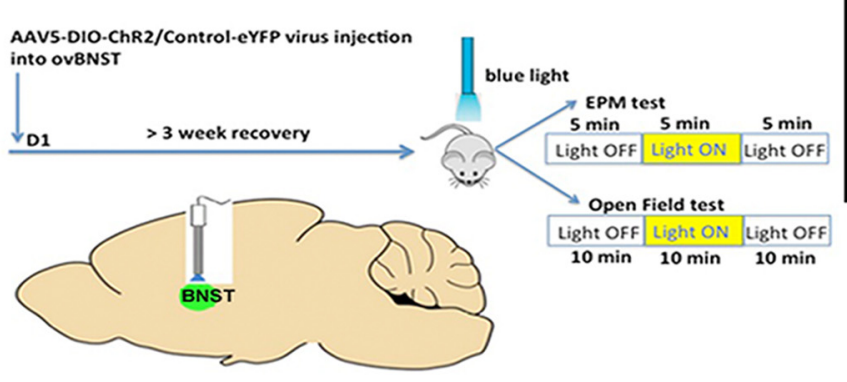

$\mathbf{F}$

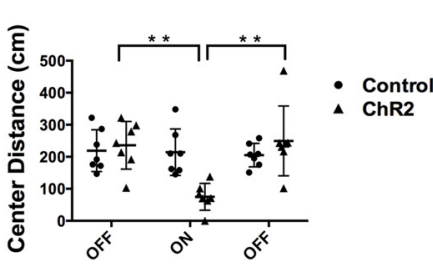

I

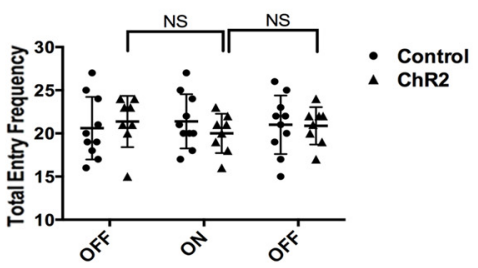

G
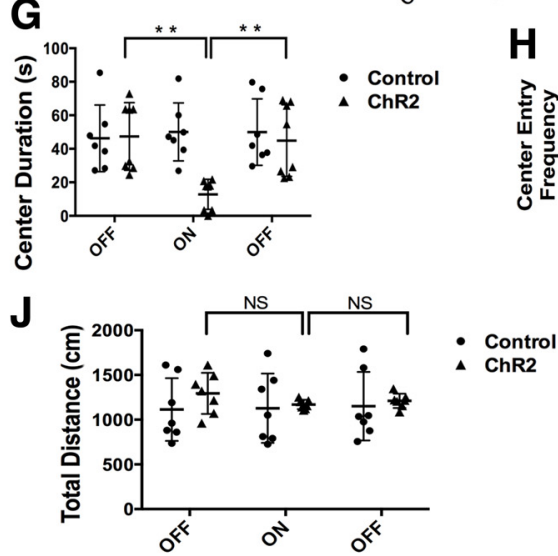

K

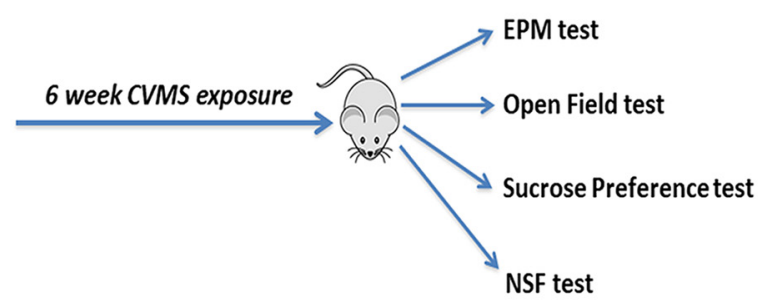

$\mathbf{N}$

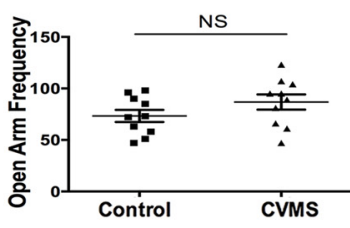

R

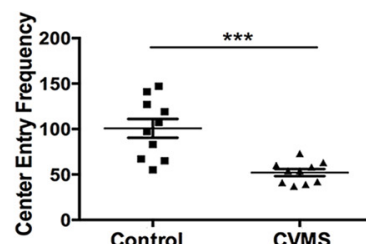

O

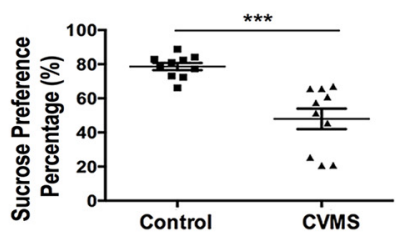

S

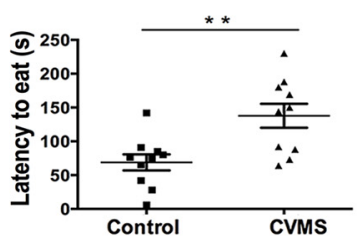

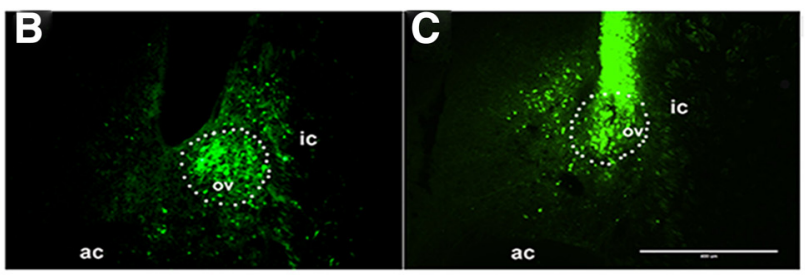

E

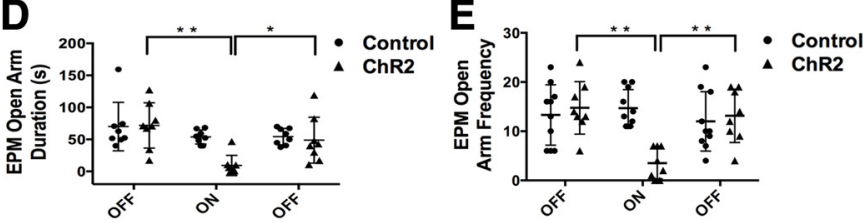

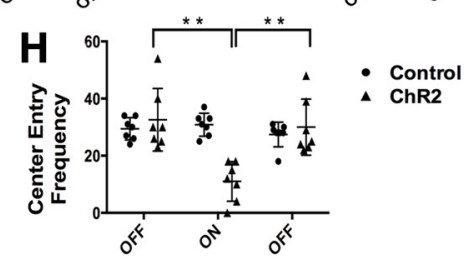

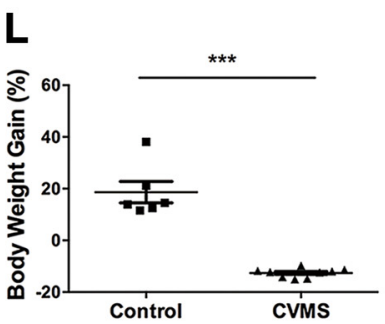

M
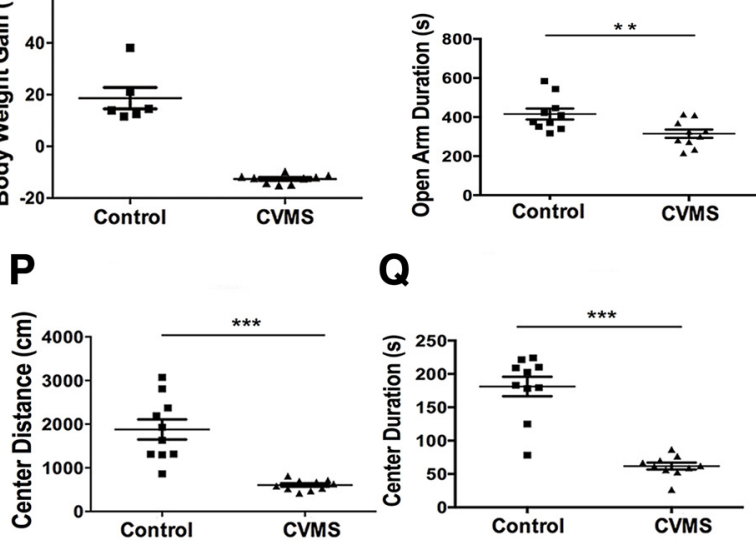

Q

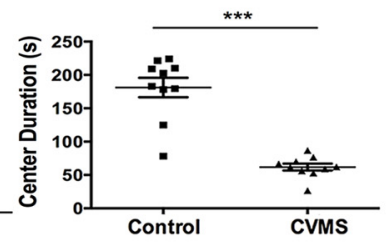

$\mathbf{T}$

U

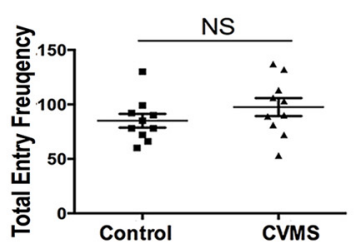

Figure 1. Acute optogenetic stimulation of ovBNST and CVMS exposure results in maladaptive behaviors. $\boldsymbol{A}$, Schematic graph showing the timeline of opsin virus (AAV5-EF1 $\alpha$-DI0-ChR2 (H134R)-eYFP, as ChR2) or control virus (AAV5-EF1 $\alpha$-DI0-eYFP, as Control) injection into the ovBNST of dopamine receptor D1a (Drd1a)-Cre transgenic mice (harboring Drd1a cells with expression restricted in the ovBNST). Mice were allowed to undergo at least 3 weeks recovery before being subjected to either EPM or OF test (both composed of three continuous sessions of light off-on-off epochs) under blue light stimulation. B, C, Example graph showing expression of Control-eYFP virus (B) and ChR2-eYFP virus ( $($ ) in the ovBNST, respectively. Scale bar, $400 \mu \mathrm{m}$. ic, Internal capsule; ac, anterior commissure; $0 v$, oval nucleus. D, Comparison of the duration time that Control $(n=8)$ mice versus ChR2 $(n=8)$ mice spent in the open arm during the light 0 FF-0N-0FF session (each $5 \mathrm{~min}$ ) in EPM. $\boldsymbol{E}$, Comparison of the frequency that Control $(n=8)$ mice versus ChR2 $(n=8)$ mice entered into the open arm during the light OFF-0N-OFF session (each 5 min) in the EPM test. $\boldsymbol{F}$, Comparison of the distance that Control $(n=7)$ mice versus ChR2 $(n=8)$ mice traveled in the middle area during the light $0 \mathrm{FF}-0 \mathrm{~N}-0 \mathrm{FF}$ session (each 10 min) in $0 \mathrm{~F}$ test. $G$, Comparison of the time duration that Control $(n=7)$ mice versus ChR2 $(n=8)$ mice spent in the center area during the light $0 \mathrm{FF}-0 \mathrm{~N}-0 \mathrm{FF}$ session (each $10 \mathrm{~min}$ ) in $0 \mathrm{~F}$ test. $\boldsymbol{H}$, Comparison of the (Figure legend continues.) 
Experimental design and statistical analysis. All data are presented as mean \pm SEM. Statistical analysis were conducted with GraphPad Prism. For optogenetics, data were analyzed using two-way ANOVA with post hoc Tukey comparisons, with light and group as independent factors. Individual sample sizes for slice patch-clamping ( $n=$ number of neurons; labeled in each figure) are reported separately for each experiment. Comparisons of $\mathrm{M}$-current $I-V$ plots between various groups were performed using a two-way ANOVA (with group as between-subject and voltage as within-subject factor, respectively), followed by post hoc Tukey comparisons. At each individual voltage (from -75 to $-25 \mathrm{mV}$ ), comparison was analyzed with unpaired two-tailed Student's $t$ test. For mEPSCs, amplitude and frequency of currents were analyzed with Mini Analysis (Synaptosoft) and compared using unpaired two-tailed Student's $t$ test. For behavior, IHC, and plasma CORT concentration, data were analyzed with one-way ANOVA and post hoc Tukey comparison. $n$ represents the number of cells or animals. Differences were considered significant when $p<0.05$.

\section{Results}

\section{Acute optogenetic activation of ovBNST increases} maladaptive avoidance behaviors in mice

Similar to Kim et al. (2013), we first confirmed that selective optogenetic activation of ovBNST induces maladaptive avoidance behaviors. To this end, we injected either a Cre-inducible ChR2 (AAV5-EF1 $\alpha$-DIO-ChR2(H134R)-eYFP) or Control virus (AAV5-EF1 $\alpha$-DIO-eYFP) into the ovBNST of dopamine receptor D1a (Drd1a)-Cre transgenic mice (Fig. 1A). In this line of dopamine receptor D1a (Drd1a)-Cre mice, within the BNST, Cre is expressed exclusively in ovBNST (Kim et al., 2013; Daniel and Rainnie, 2016). The fiberoptic was placed just above ovBNST. Figure $1 B, C$ shows an example of the expression of Control-eYFP (Fig. $1 B$ ) and ChR2-eYFP virus (Fig. 1C) in ovBNST.

In the EPM, ChR2 photoillumination of ovBNST resulted in a virus $\times$ light interaction for both open arm duration and entries (Fig. $1 D, E$; duration: $F_{(2,42)}=3.277, p=0.048$; entries: $F_{(2,48)}=$ $8.746, p=0.001)$. Specifically, ovBNST activation during the light $\mathrm{ON}$ period decreased both open arm duration (Fig. $1 D ; p=$ 0.006 and $p=0.018$, respectively) and entries (Fig. $1 E ; p=0.004$ and $p=0.008$, respectively) relative to the preceding and succeeding light OFF periods. By contrast, in mice injected with Control virus, there were no significant changes in either the open arm duration (Fig. 1D) or entries (Fig. 1E) across the light OFF/ON/OFF periods (all $p>0.05$ ). Together, these data demonstrate that acute optical stimulation of ovBNST significantly increased avoidance of the open arms.

\footnotetext{
$\leftarrow$

(Figure legend continued.) frequency that Control $(n=7)$ mice versus ChR2 $(n=8)$ mice entered into the center area during the light $0 \mathrm{FF}-0 \mathrm{~N}-\mathrm{OFF}$ session (each $10 \mathrm{~min}$ ) in $0 \mathrm{~F}$ test. $\boldsymbol{I}$, Comparison of total entry frequency of EPM test. $J$, Comparison of total $0 F$ distance. $\boldsymbol{K}$, Scheme shows that mice were subjected to a 6 week CVMS paradigm, then behavioral tests, including EPM test, sucrose preference test, $\mathrm{OF}$ test, NSF test, then were perfused for IHC. $L$, Body weight gain comparison between CVMS mice $(n=9)$ versus Control mice $(n=6)$ after 6 weeks. $\boldsymbol{M}$, Duration in the open arm in CVMS $(n=10)$ and Control mice $(n=10)$ in the EPM test. $\mathbf{N}$, Frequency in the open arm in Control $(n=10)$ versus CVMS $(n=10)$ mice in the EPM test. $\mathbf{O}$, Sucrose preference percentage in the CVMS $(n=10)$ mice versus Control mice $(n=10)$. $\boldsymbol{P}$, The distance that the mice traveled in the middle of $0 \mathrm{~F} \mathrm{test} \mathrm{in} \mathrm{the} \operatorname{CVMS}(n=10)$ mice versus Control mice $(n=10)$. $\mathbf{Q}$, The duration that the mice spent in the center of OF test in CVMS $(n=10)$ mice versus Control $(n=10)$ mice. $\boldsymbol{R}$, The entry frequency that the mice spent in the middle of 0 F test in the CVMS $(n=10)$ mice versus Control $(n=10)$ mice. $S$, The latency to eat food pellets in the NSF test in the CVMS $(n=10)$ mice versus Control $(n=10)$ mice. I, Comparison of total entry frequency in the EPM test in Control $(n=10)$ versus CVMS $(n=10)$ group. $\boldsymbol{U}$, Comparison of total distance that the mice traveled in the OF test in Control $(n=10)$ versus CVMS $(n=10 ; p>0.05)$ group. ${ }^{*} p<0.05,{ }^{* *} p<0.01,{ }^{* * *} p<0.001$. NS, Not significantly different $(p>0.05)$.
}

Similarly, in the OF, ChR2 photoillumination of ovBNST also resulted in an interaction of virus $X$ light for the center distance, center duration, and center entries (Fig. $1 F$, distance: $F_{(2,39)}=$ $6.853, p=0.003$; Fig. $1 G$, duration: $F_{(2,39)}=4.72, p=0.015$; Fig. $1 H$, entries: $\left.F_{(2,36)}=11.495, p<0.001\right)$. Specifically, ovBNST activation decreased OF center measures relative to both the preceding and succeeding light OFF periods (all $p<0.01$ ). By contrast, there were no significant changes in any of the three center measures across the light OFF/ON/OFF periods in mice injected with Control virus (all $p>0.05$ ). These data demonstrate that acute optical stimulation of ovBNST increased center avoidance.

We also compared total entry frequency in EPM test and total distance traveled in OF test during the three photo-illumination periods between ChR2 and Control mice (Fig. $1 I, J$ ). There was no significant difference between groups in either measure (all $p>0.05$ ), indicating that there was no difference in total locomotor activity. Together, these data confirmed the findings of Kim et al. (2013) and demonstrate that selective acute activation of ovBNST increases maladaptive avoidance behaviors.

\section{CVMS increases maladaptive behaviors}

While these acute optogenetic data suggest that ovBNST plays an important role in maladaptive behaviors, mood disorders, such as anxiety, are persistent illnesses that can be precipitated by chronic stress. We hypothesized that exposure to chronic stress may result in a persistent alteration to ovBNST excitability and lead to maladaptive behaviors. Therefore, we next subjected mice to a 6 week CVMS paradigm that increases maladaptive behaviors (Fig. $1 K$ ). Notably, 6 week CVMS resulted in a significant decrease in percent body weight gain compared with nonstress controls $\left(F_{(1,13)}=84.908, p<0.001\right.$; Fig. $\left.1 L\right)$. As expected, CVMS decreased sucrose preference $\left(F_{(1,18)}=23.118, p<0.001\right)$ and induced maladaptive avoidance behaviors in the EPM (open arm duration: $\left.F_{(1,18)}=8.262, p=0.01\right)$, OF (center distance: $F_{(1,18)}=$ 30.155, $p<0.001$; center duration: $F_{(1,18)}=59.24, p<0.001$; center entry frequency: $\left.F_{(1,18)}=19.50, p<0.001\right)$, and NSF tests (latency to eat: $F_{(1,18)}=10.460 ; p<0.01$, Fig. $1 M-S$ ). These data demonstrate that CVMS-exposed mice display maladaptive avoidance behaviors and decreased sucrose preference. In addition, no significant differences in total arm entry frequency in EPM or total distance in OF (Fig. 1T, $U$ ) were found (EPM total entry frequency: $F_{(1,18)}=1.477, p=0.241$; OF total distance: $\left.F_{(1,18)}=0.784, p=0.390\right)$, indicating that CVMS does not affect total locomotor activity.

\section{CVMS increases cellular excitability of ovBNST neurons by inhibiting M-currents and potentiating mEPSCs}

We next evaluated effects of CVMS on ovBNST neuronal electrophysiology. To this end, we recorded single ovBNST neurons using ex vivo slices (Fig. $2 A$ ). We first measured changes in excitatory glutamatergic neurotransmission (mEPSC example traces shown in Fig. 2B). Interestingly, CVMS significantly increased the average amplitude of mEPSCs ( $p=0.007$; Fig. $2 C$ ) of ovBNST neurons without affecting the frequency ( $p=0.499$; Fig. $2 D)$. Furthermore, CVMS significantly depolarized the resting membrane potential ( $p=0.008$; Fig. $2 E$ ) and increased the input resistance IR in ovBNST neurons ( $p=0.042$; Fig. $2 F)$. Together, these data demonstrate CVMS increased cellular excitability and caused hyperactivation of ovBNST neurons.

To determine a possible cause of this altered excitability, we next investigated M-currents. M-currents (KCNQ/Kv7 channels) are a subthreshold noninactivating voltage-dependent outward $\mathrm{K}^{+}$current that controls action potential generation and 
A

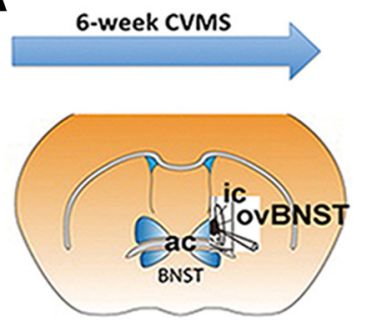

B

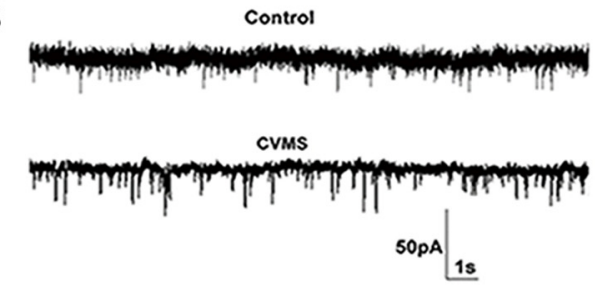

G

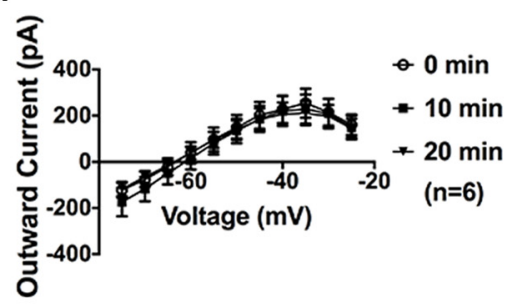

H

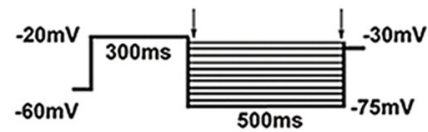

I

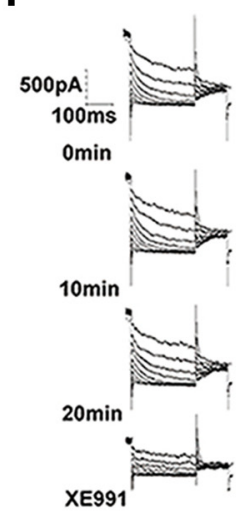

J

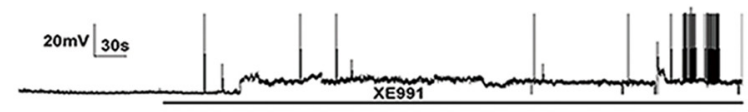

M

N

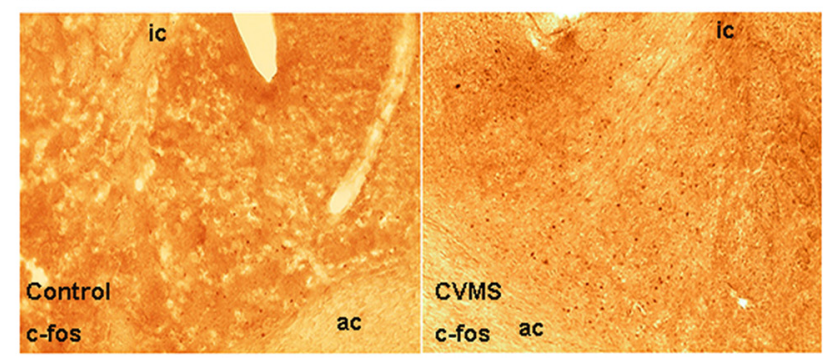

C

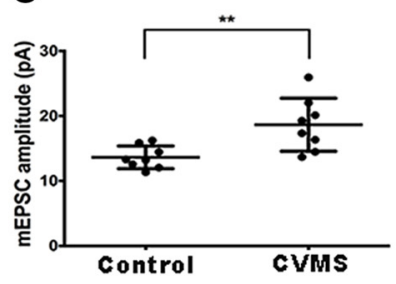

E

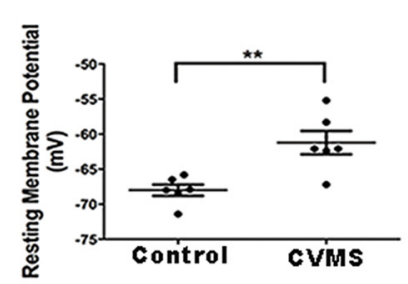

D

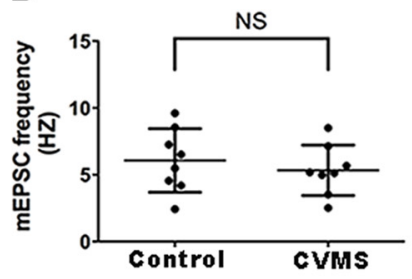

F

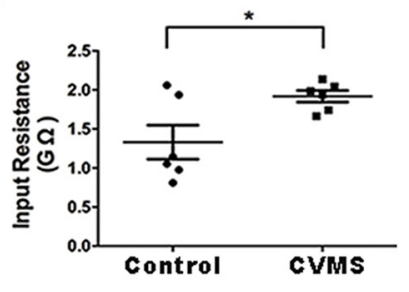

K

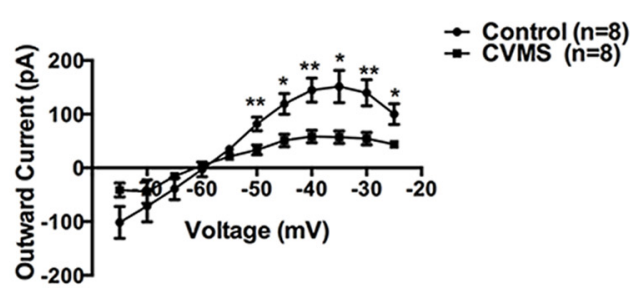

L
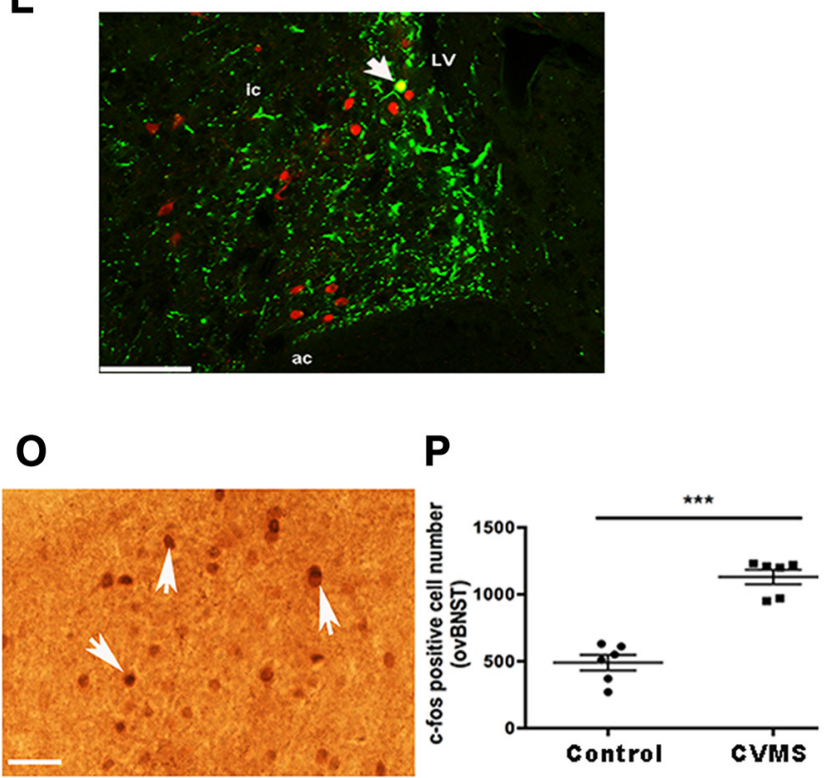

Figure 2. CVMS increases cellular excitability of ovBNST neurons by potentiating mEPSC and inhibiting M-current. $A$, Anatomy example shows the electrophysiological recording site in the ovBNST. Mice were subjected to a 6 week CVMS paradigm; then BNST coronal slices were used for whole-cell patch-clamp recording. ic, Internal capsule; ac, anterior commissure. $\boldsymbol{B}$, A typical example of comparison of $\mathrm{mEPSC}$ traces recorded in ovBNST neurons from Control versus CVMS mice. Example trace shows $50 \mathrm{pA}$ and $1 \mathrm{~s}$. C, Average mEPSC amplitude in ovBNST neurons of CVMS mice ( $n=$ 8 cells) versus Control mice ( $n=8$ cells). $\boldsymbol{D}$, Average mEPSC frequency in ovBNST neurons of CVMS mice ( $n=8$ cells) compared with Control mice ( $n=8$ cells). $\boldsymbol{E}$, Comparison of cellular resting membrane potential in ovBNST neurons from Control $(n=6$ cells) versus CVMS mice ( $n=6$ cells) revealed significant depolarized resting membrane potential in the ovBNST of CVMS mice. $F$, Comparison of cellular input resistance in ovBNST neurons from Control ( $n=6$ cells) versus CVMS mice ( $n=6$ cells). $G, I-V$ plot of M-current from -75 to $-25 \mathrm{mV}$ shows no rundown in ovBNST neurons over a period of $20 \mathrm{~min}(n=6$ cells). $\boldsymbol{H}$, The deactivation protocol used to record the M-current: from a holding potential of $-60 \mathrm{mV}$, a voltage jump to $-20 \mathrm{mV}$ ( $300 \mathrm{~ms}$ ) was followed by steps from -30 to $-75 \mathrm{mV}$ in $5 \mathrm{mV}$ increments (500 ms). I, Example of M-current traces recorded at 0, 10, and 20 min and after subsequent perfusion with KCNQ-selective channel blocker XE991 (10 min, $40 \mu \mathrm{M})$.J, An example of continuous action potential firing activity recorded in the ovBNST neuron during perfusion of selective KCNQ channel blocker XE991 ( $40 \mu \mathrm{m})$ for $10 \mathrm{~min}$ after $2 \mathrm{~min}$ baseline recording under current-clamp mode. Example trace shows $20 \mathrm{mV}$ and $30 \mathrm{~s} . K, I-V$ plot shows significantly diminished outward M-current in the ovBNST neurons ranging from -75 to $-25 \mathrm{mV}$ from CVMS versus Control mice (both $n=8$ cells per group). $L$, A representative image of confirmed CRH-positive cell located in the ovBNST after patch-clamping is designated by a white arrow. Confirmation of the neurochemical profile of recorded CRH neurons is achieved by intracellular dye labeling (AlexaFluor-633, green) followed by immunohistochemical analysis (AlexaFluor-594, red). LV, Lateral ventricle; ic, internal capsule; ac, anterior commissure. Scale bar, $50 \mu \mathrm{m} . M$, Lower-magnification example of c-fos immunostaining pattern in the anterodorsolaterl BNST BNSTadl from Control mice. $\boldsymbol{N}$, Lower-magnification example of c-fos staining pattern in the BNSTadl from CVMS mice. $\boldsymbol{O}$, White arrows point to typical c-fos-IR cells in the ovBNST. Scale bar, $50 \mu \mathrm{m}$. $\boldsymbol{P}$, Comparison of c-fos-IR cell number in the ovBNST shows higher numbers of c-fos-IR cells in the ovBNST from CVMS mice $(n=6)$ compared with Control mice $(n=6) .{ }^{*} p<0.05,{ }^{* *} p<0.01,{ }^{* * *} p<0.001$. NS, Not significantly different $(p>0.05)$. 

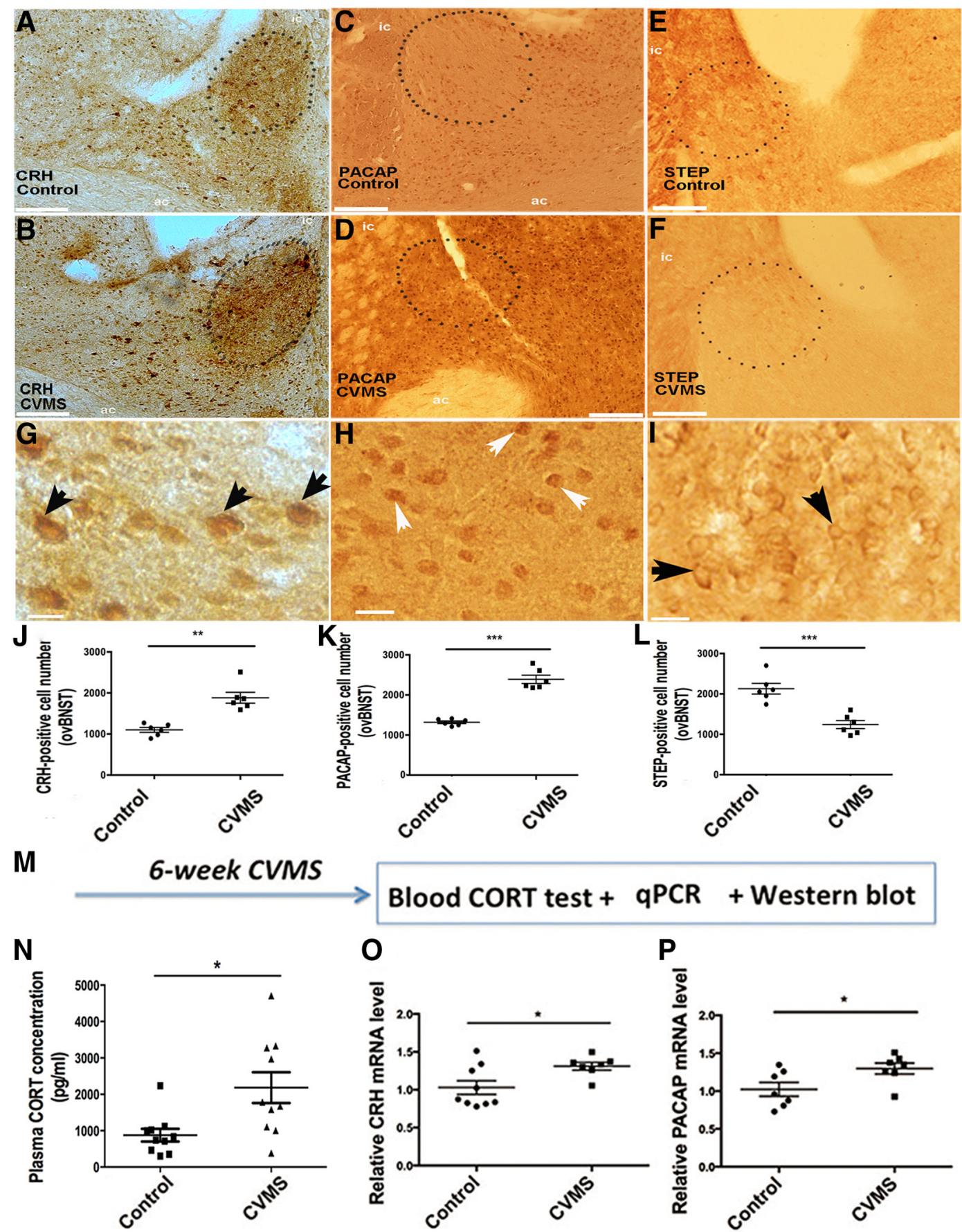

\section{Blood CORT test + qPCR + Western blot}

Q
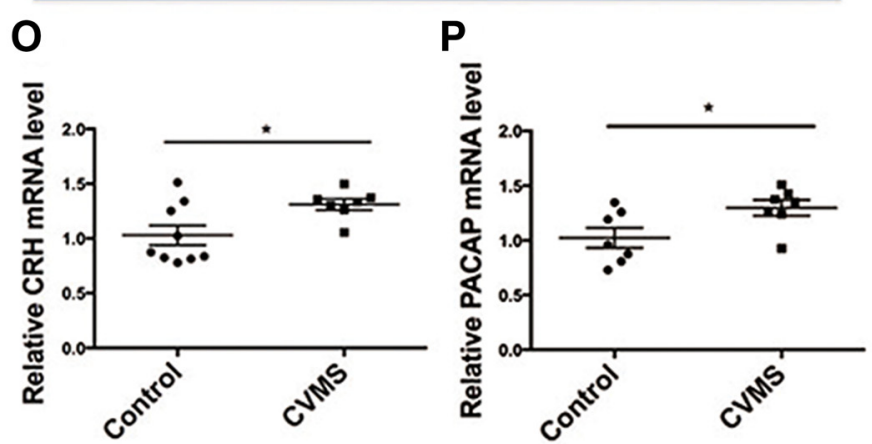

$\mathbf{R}$
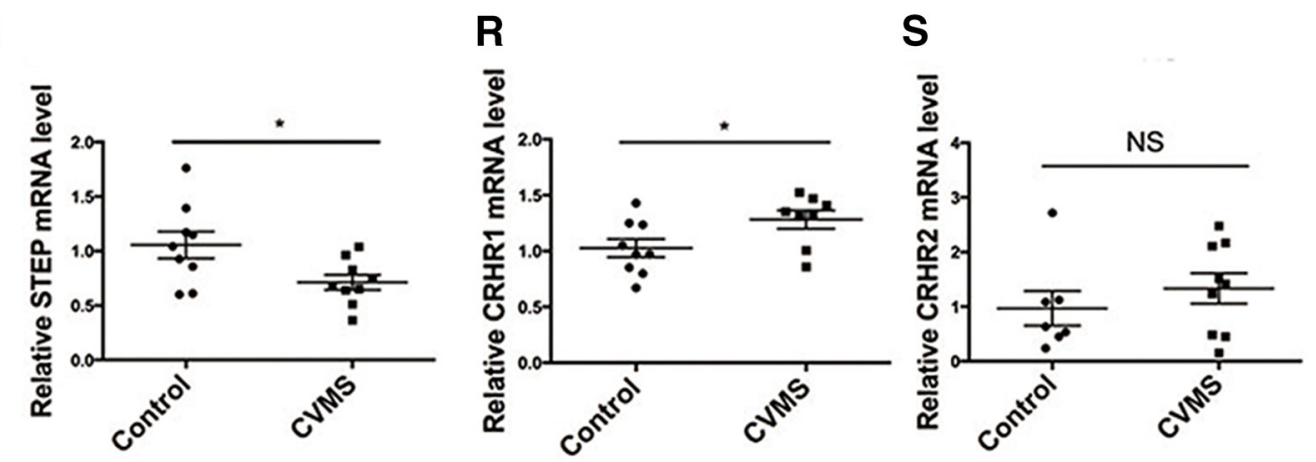

Figure 3. CVMS activates CRH-associated stress signaling components and increases mRNA expression of CRHR1 in the ovBNST. Comparison example of immunostaining pattern of CRH ( $\boldsymbol{A}$, $\boldsymbol{B})$, PACAP $(\boldsymbol{C}, \boldsymbol{D})$, and STEP $(\boldsymbol{E}, \boldsymbol{F})$ in the BNSTadl from Control mice $(\boldsymbol{A}, \boldsymbol{C}, \boldsymbol{E})$ versus CVMS mice $(\boldsymbol{B}, \boldsymbol{D}, \boldsymbol{F})$. Black dots indicate the anatomy boundary within which ovBNST is located within the BNSTadl. $10 \times$ magnification. ic, Internal capsule; ac, anterior commissure. Scale bar, $100 \mu \mathrm{m}$. G, Black arrows point to typical CRH-IR cells in the ovBNST. Scale bar, $15 \mu \mathrm{m}$. (Figure legend continues.) 
neuronal excitability (Roepke et al., 2011; Hu et al., 2016). Reduced M-currents can elicit increased excitatory cellular responses to synaptic inputs (Wang and McKinnon, 1995) and enhance cellular excitability. M-currents were recorded from ovBNST neurons using a standard deactivation-activation protocol over a voltage range $(-75$ to $-25 \mathrm{mV}$; Fig. $2 \mathrm{H})$ and calculated by determining current relaxation, the difference between the instantaneous and steady states (Fig. $2 \mathrm{H}$, arrows). The maximum M-currents were recorded at $-35 \mathrm{mV}$ (shown in Fig. 2G). We did not observe a $\mathrm{M}$-current rundown over $20 \mathrm{~min}$ of recording (amplitude decrease; example traces in Fig. 2I). However, application of the KCNQ/Kv7 channel blocker XE991 robustly decreased M-currents (Fig. 2I).

Next, firing activity of ovBNST neurons was continuously monitored in current-clamp mode (Fig. 2J). XE991 application induced action potentials after $30 \mathrm{~s}$, and 6-7 min of XE991 perfusion led to robust firing bursts indicative of cellular hyperexcitability (Fig. $2 J$ ), further demonstrating the tonic inhibitory role of M-currents in setting ovBNST neuronal excitability. Interestingly, outward $\mathrm{M}$-currents were attenuated in ovBNST neurons from CVMS mice versus Control mice (Fig. $2 K$ ), especially at higher voltages $(p=0.009,0.012,0.004,0.011,0.007$, and 0.016 at $-50,-45,-40,-35,-30$, and $-25 \mathrm{mV}$, respectively; $n=8$ cells from 6 mice for each condition), with an effect of stress $\left(F_{(1,14)}=15.299, p=0.002\right)$ and voltage $\left(F_{(10,54)}=35.01, p<\right.$ $0.001)$. At $-35 \mathrm{mV}$, the average peak current was robustly decreased [from $151.62 \pm 30.06 \mathrm{pA}$ in control $(n=8)$ to $57.02 \pm$ $11.87 \mathrm{pA}$ in CVMS $(n=8 ; p=0.004)]$. Collectively, these electrophysiology data demonstrate that CVMS significantly increases cellular excitability of ovBNST neurons by inhibiting M-currents and potentiating mEPSC amplitude. Interestingly, handling of CVMS mice led to a robust c-fos response in ovBNST that was increased relative to handled control mice (lowmagnification example figure shown in Fig. $2 M, N ; F_{(1,10)}=$ $65.29, p<0.001$; Fig. $2 O, P)$. These data further demonstrate that CVMS increases ovBNST excitability.

CVMS activates CRH-associated stress signaling components and increases mRNA expression of CRHR1 in the mice BNST We next wanted to assess potential molecular mechanisms underlying the CVMS-induced electrophysiological alterations in ovBNST. Since ovBNST harbors the highest concentration of $\mathrm{CRH}$ neurons in BNST, and $\mathrm{CRH}$ plays an important role in mediating the effects of stress (Cummings et al., 1983; Morin et al., 1999), we next assessed CVMS effects on CRH (Fig. 3A, B,

\section{$\leftarrow$}

(Figure legend continued.) $\quad 40 \times$ magnification. $\boldsymbol{H}$, White arrows point to typical PACAP-IR cells in the ovBNST. Scale bar, $30 \mu \mathrm{m}$. I, Black arrows point to typical STEP-IR cells in the ovBNST. Scale bar, $20 \mu \mathrm{m}$. J, Comparison of CRH-IR cell numbers in the ovBNST in CVMS mice $(n=6)$ compared with Control mice $(n=6) . K$, Comparison of PACAP-IR cell numbers in the ovBNST from CVMS mice $(n=6)$ compared with Control mice $(n=6)$. L, Comparison of STEP-IR cell number in the ovBNST from CVMS mice $(n=6)$ compared with Control mice $(n=6) . M$, Schematic showing the experimental design for the blood CORT collection, qPCR, and Western blot to detect changes in the mRNA and protein expression in the BNSTadl after mice were subjected to the 6 week CVMS paradigm. $\boldsymbol{N}$, Basal plasma CORT concentration in the CVMS group $(n=10)$ versus Control group $(n=10)$. $\boldsymbol{O}$, Expression of $(r h$ mRNA in the BNSTadl of the $\operatorname{CVMSgroup~}(n=7)$ versus Control group $(n=9)$. P, Pacap mRNA expression comparison in the BNSTadl from CVMS $(n=7)$ versus Control $(n=7)$ group. $\boldsymbol{Q}$, Step mRNA expression comparison in the BNSTadl from CVMS $(n=9)$ versus Control $(n=9)$ group. $\boldsymbol{R}$, Crhr1 mRNA expression in the BNSTadl of the CVMS $(n=8)$ group compared with Control $(n=9)$ group. S, Crhr2 mRNA expression comparison in the BNSTadl from Control $(n=7)$ versus CVMS $(n=9)$ group. ${ }^{*} p<$ $0.05,{ }^{* *} p<0.01,{ }^{* * *} p<0.001$. NS, Not significant.
Control vs CVMS), PACAP (an upstream stress regulator of CRH; Fig. 3C,D, Control vs CVMS), and STEP (an intracellular $\mathrm{CRH}$ receptor inhibitor; Fig. $3 E, F$, Control vs CVMS) in BNST. CVMS increased the number of $\mathrm{CRH}^{+}$cells (Fig. 3G) in ovBNST relative to Control $\left(F_{(1,10)}=28.93, p<0.01\right.$; Fig. $\left.3 J\right)$. Interestingly, CVMS also significantly increased $\mathrm{PACAP}^{+}$cells (Fig. $3 H ; F_{(1,10)}=98.36, p<0.001$; Fig. $3 K$ ) and decreased STEP $^{+}$cells (Fig. 3I; $F_{(1,8)}=20.099, p<0.01$; Fig. $3 L$ ) in ovBNST. Together, these data demonstrate that CRH-associated stress signaling is significantly activated in ovBNST after CVMS. We also evaluated CORT concentrations in blood plasma (Fig. $3 M)$ and found significantly higher basal CORT levels in CVMS mice relative to control $\left(F_{(1,18)}=12.281, p=0.015\right.$; Fig. $\left.3 N\right)$. Importantly, post hoc immunostaining of our ex vivo slices also confirmed that all electrophysiology recordings in Figure 2 were from $\mathrm{CRH}^{+}$cells (Fig. $2 L$ ).

To complement these immunohistochemical findings, we next assessed mRNA expression of Crh, Pacap, Step, and the CRH receptors Crhr1 and Crhr2 in BNSTadl by qPCR (experimental scheme shown in Fig. $3 M)$. CVMS significantly increased the mRNA expression levels of $\operatorname{Crh}\left(F_{(1,14)}=6.303, p=0.018\right.$; Fig. $30)$, Pacap $\left(F_{(1,12)}=5.597, p=0.037\right.$; Fig. $\left.3 P\right)$, and Crhrl $F_{(1,15)}$ $=4.985, p=0.041$; Fig. $3 R)$, and decreased mRNA expression of Step $\left(F_{(1,16)}=5.877, p=0.031\right.$; Fig. 3Q) in BNSTadl relative to nonstressed controls. By contrast, CVMS did not affect mRNA expression of $\operatorname{Crhr} 2\left(F_{(1,14)}=0.750, p=0.403\right.$; Fig. $\left.3 S\right)$. Together, these qPCR results confirmed the IHC results that CVMS activates $\mathrm{CRH}$ signaling in BNST, and demonstrated that CVMS activates CRHR1 in BNST.

\section{Infusion of CRHR1-selective antagonist R121919 into ovBNST reversed CVMS effects on behavior and electrophysiology}

Since our results demonstrate that CVMS induces CRHR1 activation and increases cellular excitability of $\mathrm{CRH}$ neurons in ovBNST, we next explored whether CVMS-induced maladaptive behaviors are mediated by CRHR1 in BNST. To this end, CRHR1-selective antagonist R121919 (1 $\mu \mathrm{g}$, dissolved in $0.5 \mu \mathrm{l}$ saline) was infused into ovBNST of CVMS and control mice continuously for $7 \mathrm{~d}$ (experiment scheme shown in Fig. 4A,B) and avoidance behaviors were assessed. Interestingly, chronic R121919 infusions into ovBNST of CVMS mice significantly increased EPM open arm duration and OF center distance, center duration, and center entries [EPM open arm duration: $F_{(3,30)}=$ 10.751, $p=0.010$; CVMS vs CVMS + R121919, $p=0.042$ (Fig. $4 C)$; OF center distance: $F_{(3,30)}=16.496, p<0.001$; CVMS vs CVMS + R121919, $p=0.033$ (Fig. 4E); OF center duration: $F_{(3,29)}=42.228, p<0.001 ;$ CVMS vs CVMS + R121919, $p=$ 0.047 (Fig. $4 F$ ); OF center entries: $\operatorname{ANOVA~}_{(3,30)}=10.404, p<$ 0.001; CVMS vs CVMS + R121919, $p=0.013$ (Fig. 4G)].

Chronic R121919 infusions into BNST of CVMS mice also decreased NSF latency to eat and increased sucrose preference [NSF: $F_{(3,29)}=7.015, p=0.001$; CVMS vs CVMS + R121919 $p=$ 0.010, Fig. $4 H$; SPT: $F_{(3,29)}=12.331, p<0.001$; CVMS vs CVMS $+\mathrm{R} 121919 p=0.004$, Fig. 4I]. R121919 did not affect EPM open arm entries $\left(F_{(3,30)}=0.849, p=0.478\right.$; Fig. $\left.4 D\right)$. Importantly, R121919 infusions into the BNST of Control mice had no significant effects on any of these behavioral parameters (Control vs Control + R121919: $p>0.05$ for all).

Interestingly, when R121919 ( $1 \mu \mathrm{M})$ was preincubated with BNST brain slices, the CVMS-induced decrease in M-current amplitude of ovBNST CRH neurons was also reversed (Fig. $4 \mathrm{~J}$ ), with a significant effect of group $\left(F_{(3,26)}=6.347, p=0.002\right)$ and 
A

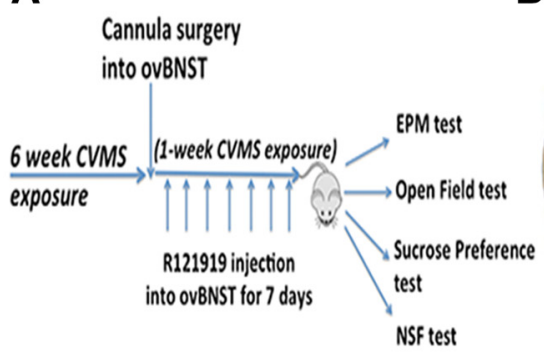

B

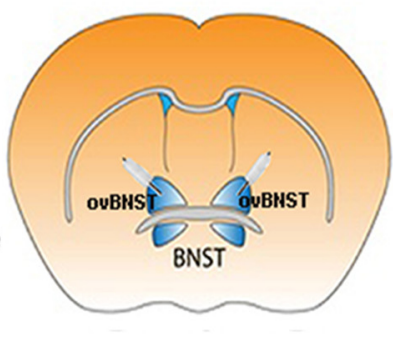

C

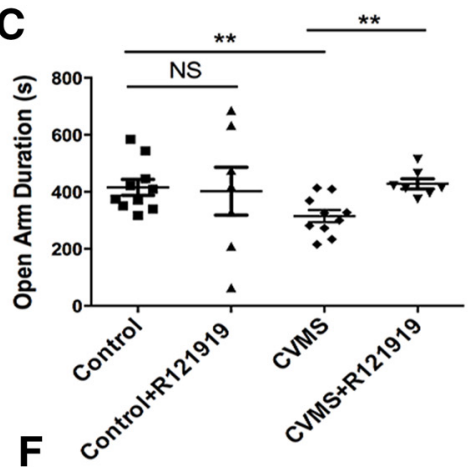

E
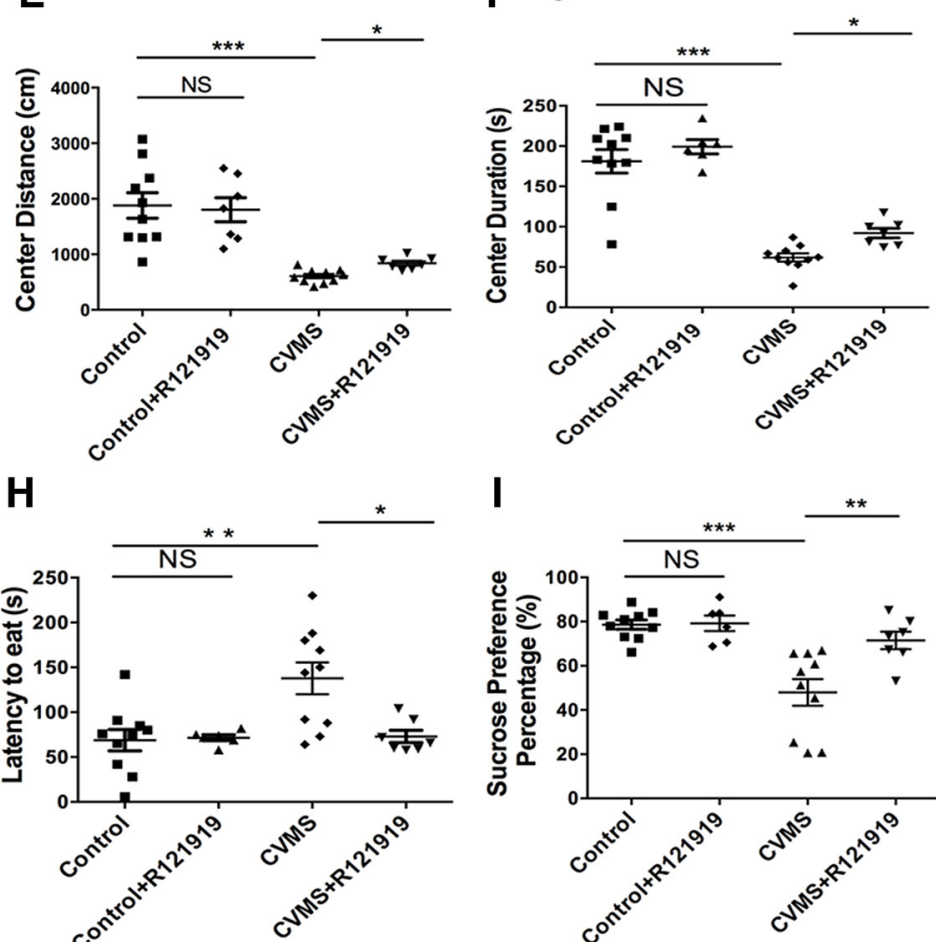

G

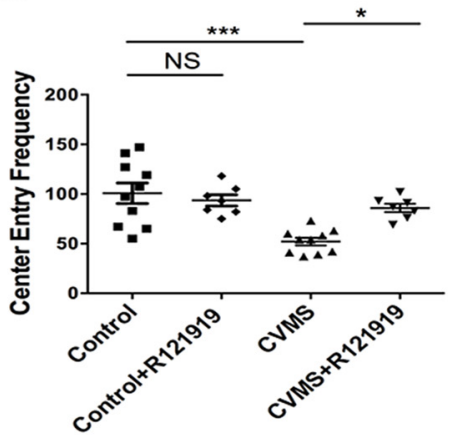

H

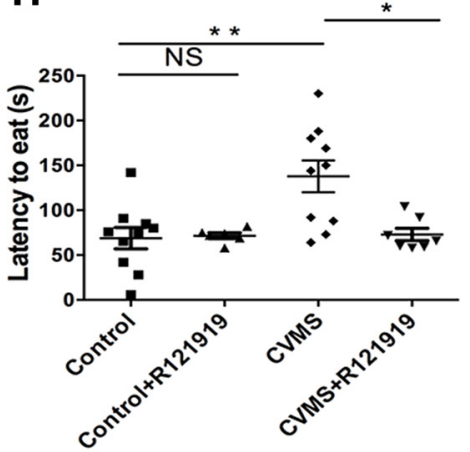

- Control ( $n=8)$

J

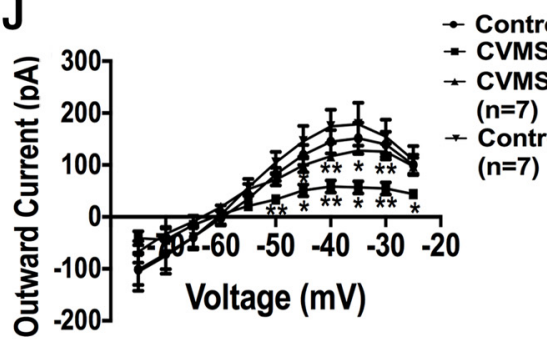

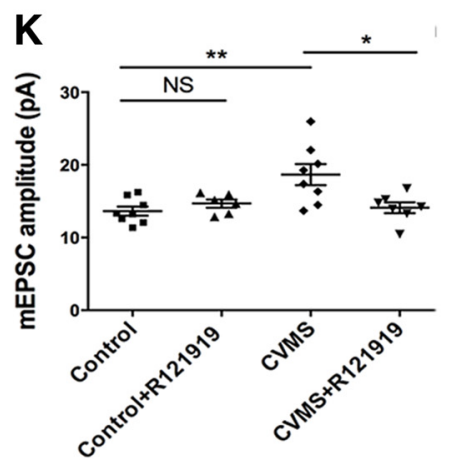

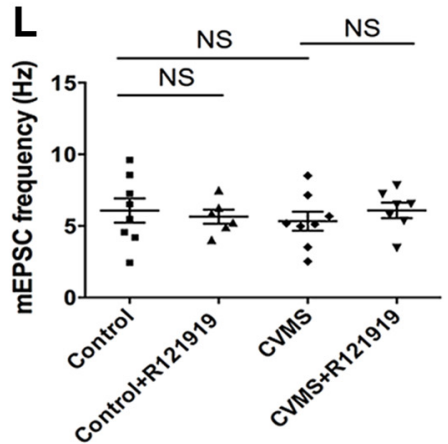

Figure 4. CRHR1-selective antagonist R121919 infusion into ovBNST reverses the electrophysiological and behavioral effects of CVMS. A, Schematics shows that CRHR1-selective antagonist R121919 (1 $\mu \mathrm{g}$ dissolved in $0.5 \mu \mathrm{l}$ saline) was chronically infused into the ovBNST of CVMS mice through a cannula for a continuous period of $7 \mathrm{~d}$ to compare its effects on behaviors in the EPM test, OF test, SPT test, and NSF test. CVMS exposure was continuously present during the 1 week chronic R121919 infusion period. $\boldsymbol{B}$, Anatomical example showing the location (Figure legend continues.) 

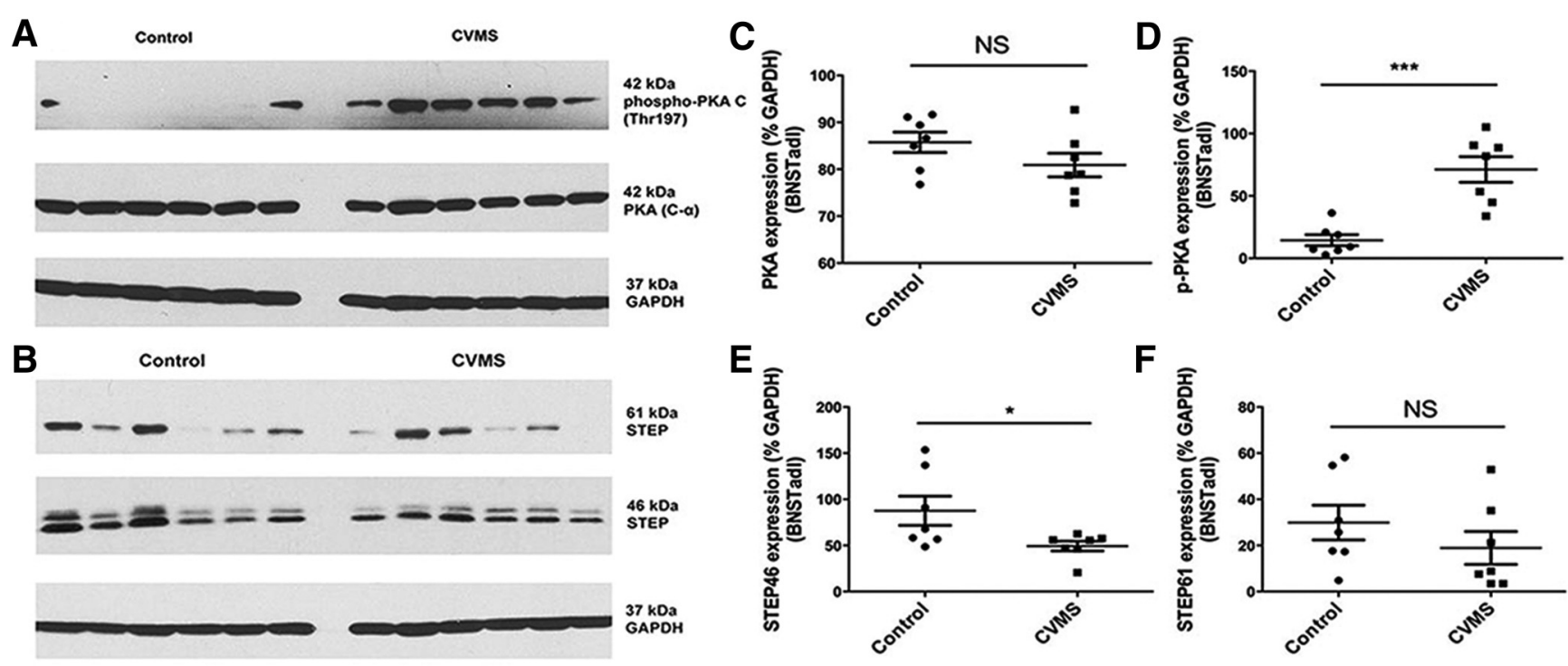

Figure 5. CVMS induces PKA activation in the BNSTadl. $A$, Western blot example showing comparison of expression of $42 \mathrm{kDa}$ phospho-PKA C (Thr197) (first lane) and $42 \mathrm{kDa}$ PKA (C- $\alpha$ ) (second lane) in the BNSTadl from Control (left) versus CVMS (right) mice; $37 \mathrm{kDa}$ GAPDH was used as endogenous control (bottom). $\boldsymbol{B}$, Western blot example showing comparison of expression of $61 \mathrm{kDa}$ membrane isoform of STEP61 and $46 \mathrm{kDa}$ cytosolic isoform of STEP46 in the BNSTadl from Control (left) versus CVMS (right) mice; $37 \mathrm{kDa}$ GAPDH was used as endogenous control (bottom). C, Quantification of total PKA protein expression level in the BNSTadl compared between Control $(n=7)$ versus CVMS $(n=7)$ mice. D, Quantification and comparison of p-PKA (Thr197) expression level in BNSTadl from Control $(n=7)$ versus CVMS $(n=7)$ mice revealed higher expression of p-PKA from the CVMS mice compared with Control mice. E, Quantification of cytosolic STEP46 expression revealed significantly higher expression in the BNSTadl from Control $(n=7)$ versus CVMS $(n=7)$ mice. $F$, Quantification and comparison of membrane STEP61 expression in the BNSTadl from Control $(n=7)$ versus CVMS $(n=7)$ mice revealed no significant difference between these two groups. ${ }^{*} p<0.05$, ${ }^{* * *} p<0.001$. NS, Not significant.

voltage $\left(F_{(10,54)}=60.2, p<0.001\right)$. M-currents were restored in slices from CVMS + R121919 mice compared with CVMS slices at higher voltages $(p=0.013,0.003,0.018$, and 0.007 at -45 , $-40,-35$, and $-30 \mathrm{mV}$, respectively). M-current peak value at $-35 \mathrm{mV}$ was reversed from an average $57.02 \pm 11.87 \mathrm{pA}$ in CVMS slices $(n=8)$ to $127.65 \pm 9.7 \mathrm{pA}$ in CVMS + R121919 slices $(n=7 ; p=0.018)$.

Similarly, for mEPSC amplitude, a significant group effect was found $\left(F_{(3,28)}=6.091, p=0.003\right)$, and mEPSC amplitude was decreased in CVMS $+\mathrm{R} 121919$ relative to CVMS slices $(p=$ 0.012; Fig. $4 K)$. mEPSC frequency was not changed $\left(F_{(3,28)}=\right.$ $0.307, p=0.820$; Fig. $4 L$ ). Importantly, R121919 infusions into BNST slices from Control mice had no significant effects on any

$\leftarrow$

(Figure legend continued.) of the cannulas that were bilaterally inserted into the ovBNST. C, Duration time spent in the open arm in the EPM in CVMS + R121919 $(n=7)$ compared with CVMS mice $(n=10)$; and in Control + R121919 $(n=6)$ compared with Control $(n=10)$ mice. D. The frequency of open arm entries in CVMS + R121919 $(n=7)$ compared with CVMS mice $(n=10)$; and in Control + R121919 ( $n=7)$ compared with Control $(n=10)$ mice. E, Distance traveled in the middle of OF by CVMS + R121919 mice $(n=7)$ compared with CVMS mice $(n=$ 10); and in Control + R121919 $(n=7)$ compared with Control $(n=10)$ mice. $\boldsymbol{F}$, Duration of middle time in OF in CVMS + R121919 mice $(n=7)$ compared with CVMS mice $(n=10)$; and in Control + R121919 $(n=6)$ compared with Control $(n=10)$ mice. G, Frequency of middle entries in the OF by CVMS + R121919 mice $(n=7)$ compared with CVMS mice $(n=10)$; and in Control + R121919 $(n=6)$ compared with Control $(n=10)$ mice. $\boldsymbol{H}$, Latency to pellet consumption in the NSF in CVMS + R121919 mice $(n=7)$ compared with CVMS mice $(n=10)$; and in Control $+\mathrm{R} 121919(n=7)$ compared with Control $(n=10)$ mice. I, Sucrose preference percentage in CVMS + R121919 mice $(n=7)$ compared with CVMS mice $(n=10)$; and in Control + R121919 $(n=7)$ compared with Control $(n=10)$ mice. J, Preincubation of BNST brain slices from CVMS mice or Control mice with $10 \mu \mathrm{M}$ PKA-selective antagonist R121919 ( $n=7$ cells) in each condition for 30 min and $I-V$ curve of outward M-current in neurons from CVMS mice ( $n=8$ cells) compared with CVMS ( $n=8$ cells) or Control mice ( $n=8$ cells). $\boldsymbol{K}$, mEPSC amplitude in CRH neurons with R121919 preincubation ( $n=7$ cells) compared with untreated neurons from CVMS mice ( $n=8$ cells). $L$, mEPSC frequency in CRH neurons with R121919 preincubation ( $n=7$ cells) compared with untreated neurons from CVMS mice $(n=$ 8 cells). ${ }^{*} p<0.05,{ }^{* *} p<0.01,{ }^{* * *} p<0.001$. NS, Not significantly different. of these electrophysiology measures (Fig. $4 J-L ; p>0.05$ for all). Collectively, these results demonstrate that R121919 infusions into ovBNST reversed the effects of CVMS on avoidance behaviors and BNST electrophysiology. These data strongly implicate BNST CRHR1 as a major mediator of the effects of CVMS.

\section{CVMS activates PKA in BNST}

CRHR1 is a Gs protein-coupled receptor linked to adenylyl cyclase (AC) that upon activation results in PKA activation. Therefore, we next investigated whether CVMS results in PKA activation in BNSTadl. To this end, we assessed protein expression levels of PKA (using an antibody recognizing the PKA C- $\alpha$ subunit) and its activated form p-PKA (using an antibody recognizing Thr197 phosphorylated-PKA-C; Fig. 5A) in BNSTadl tissue punches from CVMS and control mice. While total PKA levels did not differ in CVMS mice $(n=7)$ versus control $(n=7$; $p=0.171$; Fig. $5 C)$, p-PKA expression in BNSTadl was increased by CVMS $(n=7)$ versus control $(n=7 ; p=0.0003$; Fig. $5 D)$, indicating that CVMS induces PKA activation in BNSTadl. We also assessed STEP protein expression in BNSTadl tissue punches (Western blot example figure shown in Fig. $5 B$ ). Whereas the membrane isoform STEP61 did not differ in CVMS mice versus Control mice ( $p=0.31$; Fig. $5 F)$, CVMS significantly decreased expression of the cytosolic isoform STEP46 in BNSTadl $(p=$ 0.026; Fig. 5E).

\section{PKA-selective antagonist $\mathrm{H89}$ reverses CVMS effects on} behavior and electrophysiological parameters in BNST

We next assessed whether PKA activation in ovBNST also mediates CVMS effects on M-currents and mEPSCs of CRH neurons. When ex vivo brain slices were preincubated with the PKAselective antagonist H89 (10 $\mu \mathrm{M})$ for $30 \mathrm{~min}$, the CVMS-induced decrease in the outward M-currents of ovBNST CRH neurons (confirmed by post hoc immunostaining) was significantly attenuated at higher voltages, with a significant effect of group $\left(F_{(3,25)}\right.$ 

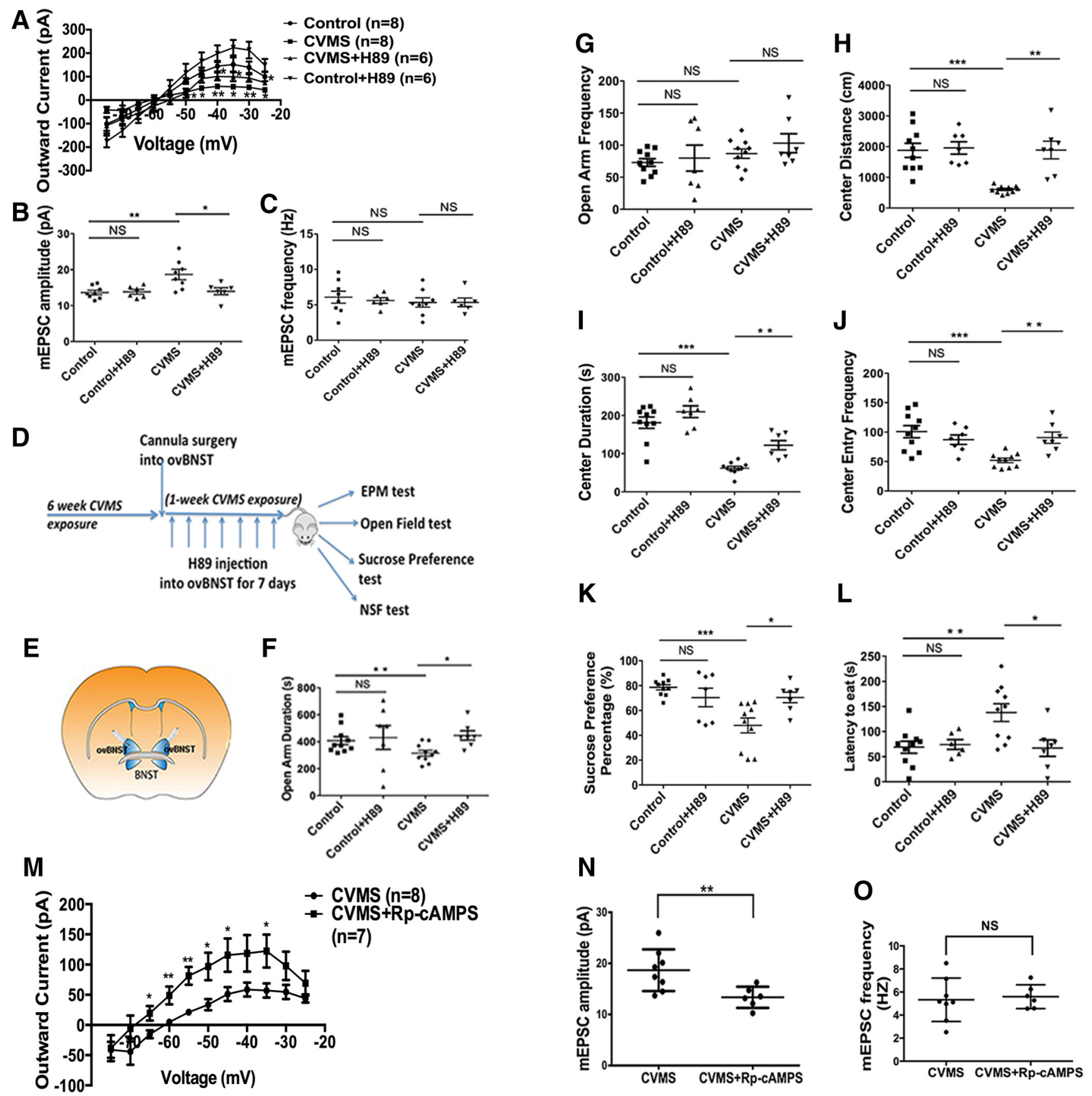

Figure 6. PKA-selective antagonists $\mathrm{H} 89$ and Rp-CAMPS infused into ovBNST reverse the electrophysiological and behavioral effects of CVMS. $A$, Preincubation of BNST brain slices from CVMS mice with $10 \mu \mathrm{m}$ PKA-selective antagonist $\mathrm{H} 89$ ( $n=6$ cells) for $30 \mathrm{~min}$ and $I-V$ curve of outward M-current from the ovBNST of CVMS mice $(n=8$ cells) and Control mice ( $n=8$ cells). $B$, mEPSC amplitude from $\mathrm{H} 89$ preincubation $(n=6$ cells) compared with untreated cells $(n=8)$ from CVMS mice. C, mEPSC frequency from H89 preincubation ( $n=6$ cells) compared with untreated cells $(n=8)$ from CVMS mice ( $n=8$ cells). $\boldsymbol{D}$, Schematics of cannula surgery shows that PKA-selective antagonist H89 was chronically infused into ovBNST of CVMS mice through a cannula for a continuous $7 \mathrm{~d}$ to compare its effect on the anxiety-associated behavior (in the EPM test, OF test, SPT test, and NSF test). CVMS exposure was continuously present during the 1 week chronic H89 infusion period. $E$, Anatomical example showing the location of the cannulas that were bilaterally inserted into the ovBNST. $F$, Duration time that mice spent in open arm of EPM test after infusion of PKA-selective antagonist H89 (CVMS + H89; $n=7$ ) into the ovBNST compared with saline-infused CVMS mice $(n=10)$. $\mathbf{G}$, Frequency that mice entries into open arm of EPM test after infusion of H89 (CVMS + H89; $n=7$ ) compared with saline-infused CVMS mice $(n=10)$. $\boldsymbol{H}$, Distance traveled in the middle of OF test after infusion of H89 (CVMS + H89; $n=7)$ compared with saline-infused CVMS mice $(n=10)$.I, Duration spent in the middle of OF test after infusion of H89 (CVMS + H89; $n=7)$ compared with saline-infused CVMS mice $(n=10) . J$, Frequency of middle zone entries in OF after infusion of H89 (CVMS + H89; $n=7)$ compared with saline-infused CVMS mice $(n=10 ; p<05)$. $\boldsymbol{k}$, Sucrose preference percentage after infusion of H89 (CVMS + H89; $n=$ 7) compared with saline-infused CVMS mice $(n=10)$. $L$, Latency to eat food pellet after infusion of H89 (CVMS + H89; $n=7)$ compared with saline-infused CVMS mice $(n=10)$. $M, I-V$ plot of outward M-current after Rp-cAMPS intracellular dialysis $(n=7)$ in ovBNST CRH neurons compared with untreated cells from CVMS mice $(n=8)$. $N$, mEPSC amplitude after Rp-cAMPS dialysis $(n=$ 6) in ovBNST CRH neurons compared with untreated cells from CVMS mice $(n=8) .0, \mathrm{mEPSC}$ freuquency after Rp-cAMPS dialysis $(n=6)$ in ovBNST CRH neurons compared with untreated cells from CVMS mice $(n=8) .{ }^{*} p<0.05,{ }^{* *} p<0.01,{ }^{* * *} p<0.001$. NS, Not significantly different $(p>0.05)$. 
$=2.701, p=0.042)$ and voltage $\left(F_{(10,54)}=15.521, p<0.001\right.$; Fig. $6 A)$. M-currents were increased in slices from CVMS + H89 mice compared with CVMS slices at higher voltages $(p=0.036,0.047$, and 0.046 at $-40,-35$, and $-25 \mathrm{mV}$, respectively). At $-35 \mathrm{mV}$, the outward M-current peak value was increased to $99.96 \pm 19.07$ pA $(n=6)$ in CVMS slices preincubated with H89 compared with $57.02 \pm 11.87 \mathrm{pA}(n=8)$ in CVMS slices $(p=0.047$; Fig. $6 A)$. At all voltages, no significant effects were found of $\mathrm{H} 89$ infusion into control mice ( $p>0.05$ for all).

Similarly, for mEPSC amplitude, a significant group effect was found $\left(F_{(3,24)}=6.032, p=0.003\right)$. The CVMS-induced mEPSC increase in amplitude in ovBNST CRH neurons was significantly decreased when slices were preincubated with H89 for $30 \mathrm{~min}$ $(p=0.021$; Fig. $6 B)$. By contrast, for mEPSC frequency, no significant group effect was found $\left(F_{(3,24)}=0.276, p=0.842\right.$; Fig. $6 C)$. Importantly, H89 preincubation had no significant effects on mEPSCs in ovBNST CRH neurons of Control slices (amplitude: $p=0.843$; frequency: $p=0.630$; Fig. $6 B, C$ ). Together, these results suggest that the effects of CVMS on M-currents and mEPSC amplitude in ovBNST CRH neurons are mediated by PKA activation.

Next, we examined whether BNST PKA activation also mediates the behavioral effects of CVMS by chronically infusing the PKA-selective antagonist H89 ( $25 \mathrm{nM}$, dissolved in $0.5 \mu$ l saline) directly into ovBNST (Fig. 6D,E). Chronic H89 infusions into BNST of CVMS mice significantly increased EPM open arm duration $\left(F_{(3,30)}=10.872, p=0.026\right.$; Fig. $\left.6 F\right)$, OF center distance $\left(F_{(3,30)}=11.892, p<0.001\right.$; Fig. $\left.6 H\right)$, center duration $\left(F_{(3,30)}=\right.$ $30.416, p<0.001$; Fig. $6 I)$, and center entries $\left(F_{(3,30)}=7.542, p<\right.$ 0.001 ; Fig. $6 J)$. H89 infusion also increased sucrose preference $\left(F_{(3,30)}=7.552, p=0.001\right.$; Fig. $\left.6 \mathrm{~K}\right)$ and decreased NSF latency to eat $\left(F_{(3,29)}=5.720, p=0.003\right.$; Fig. $\left.6 L\right)$. H89 did not affect EPM open arm entries in CVMS mice $\left(F_{(3,30)}=1.141, p=0.348\right.$; Fig. $6 G)$. Importantly, chronic H89 infusions into BNST of Control mice had no effects on any of these behavioral measures $(p>0.05$ for all). Together, these results demonstrate that blockade of PKA activity in BNST can reverse the maladaptive behavioral effects of CVMS.

\section{PKA-antagonist Rp-cAMPS reverses CVMS effects on electrophysiological parameters in BNST slices}

To confirm the H89 effects on ovBNST electrophysiology in CVMS mice, another PKA antagonist, nonhydrolyzable cAMP analog Rp-cAMPS (100 $\mu \mathrm{M})$ was used to occlude the activation of intracellular PKA by intracellular dialysis 5 min before recording ovBNST CRH neurons in slices from CVMS mice. When cells were dialyzed with Rp-cAMPS, M-currents were significantly increased, with a significant effect of group (Fig. $6 M ; F_{(1,13)}=6.794$, $p=0.023 ; p=0.017,0.006,0.002,0.018,0.041$, and 0.039 at -65 , $-60,-55,-50,-45$, and $-35 \mathrm{mV}$, respectively). At $-35 \mathrm{mV}$, the outward M-current peak value was increased to $122.31 \pm$ $27.28 \mathrm{pA}(n=7)$ in Rp-cAMPS dialyzed cells compared with $57.02 \pm 11.87 \mathrm{pA}(n=8 ; p=0.039)$ in CVMS slices (Fig. $6 M)$. Similarly, the CVMS-induced increased mEPSC amplitude in ovBNST CRH neurons was significantly decreased in dialyzed cells compared with those in CVMS slices ( $p=0.009$; Fig. $6 N)$. Average mEPSC frequency was not different between the two groups ( $p=0.741$; Fig. 60 ). Collectively, these Rp-cAMPS data confirm the H89 electrophysiological results and demonstrate that PKA activation mediates the effects of CVMS on M-currents and mEPSC amplitude in ovBNST CRH neurons.

\section{CVMS effects persist when R121919 is coadministered with PKA activator forskolin}

Since CRHR1 is Gs-coupled and leads to PKA activation, and blocking PKA activation in ovBNST reverses CVMS effects on behavior and electrophysiology, we next investigated whether PKA indeed acts downstream of CRHR1 to mediate the effects of CVMS. To this end, we tested whether CVMS effects on behavior and ovBNST electrophysiology persisted when CRHR1 was blocked but PKA was activated. Interestingly, when forskolin (120 nM), which activates PKA by increasing cAMP levels, was coadministered with the CRHR1-selective antagonist R121919 (1 $\mu \mathrm{g}$ ) into ovBNST for $7 \mathrm{~d}$ (Fig. $7 \mathrm{~A}$ ), we found that the maladaptive behaviors induced by CVMS persisted. When CVMS mice were compared with CVMS mice that had R121919 and forskolin coinfused into ovBNST, we found no significant differences in EPM open arm duration $\left(F_{(1,15)}=1.145, p=0.301\right.$; Fig. $\left.7 B\right)$, EPM open arm entry frequency $\left(F_{(1,15)}=1.947, p=0.183\right.$; Fig. $7 C)$, OF center distance $\left(F_{(1,15)}=3.011, p=0.103\right.$; Fig. $\left.7 D\right), \mathrm{OF}$ center duration $\left(F_{(1,15)}=3.111, p=0.098\right.$; Fig. $\left.7 E\right)$, and $\mathrm{OF}$ center entries $\left(F_{(1,15)}=3.006, p=0.103\right.$; Fig. $\left.7 F\right)$. There was also no significant difference in NSF latency to eat $\left(F_{(1,15)}=1.479\right.$, $p=0.243$; Fig. $7 G)$ or sucrose preference $\left(F_{(1,15)}=1.115, p=\right.$ 0.308; Fig. $7 H$ ) between CVMS and CVMS + R121919 + forskolin mice.

We further preincubated ex vivo BNST slices from CVMS mice with R121919 (1 $\mu \mathrm{M})$ and forskolin $(50 \mu \mathrm{M})$ for $30 \mathrm{~min}$, and then recorded M-currents and mEPSCs in ovBNST CRH neurons. Similar to the behavioral results, we found no difference in M-currents between CVMS and CVMS + R121919 + forskolin slices $\left(F_{(1,13)}=1.068, p=0.320\right)$. At $-35 \mathrm{mV}$, the average M-current peak value was $57.02 \pm 11.87 \mathrm{pA}(n=8)$ in BNST slices from CVMS mice, compared with $44.62 \pm 23.25 \mathrm{pA}(n=7$; $p=0.841$ ) in CVMS + R121919 + forskolin slices (Fig. 7I). Furthermore, there were no differences in mEPSC amplitude $(p=0.856$; Fig. $7 J)$ and frequency $(p=0.727$; Fig. $7 K)$ in ovBNST CRH neurons between CVMS + R121919 + forskolin and CVMS BNST slices. Collectively, these results indicate that the effects of CVMS on behavior and BNST electrophysiology parameters persist when CRHR1 is blocked and PKA is simultaneously activated. Therefore, CVMS induces PKA activation downstream of CRHR1, and PKA thus likely acts as one the final effector to mediate the maladaptive effects of CVMS.

\section{Bath application of CRH mimics the effects of CVMS on M- currents and mEPSCs in ovBNST CRH neurons}

While the above pharmacological results demonstrate that a signaling pathway through CRHR1 and PKA is necessary for the effects of CVMS on ovBNST electrophysiology, we also wanted to investigate whether $\mathrm{CRH}$-mediated activation of this pathway is sufficient for directly mediating these maladaptive effects. CRH can directly increase glutamatergic transmission in BNST (Kash et al., 2008), so we tested whether exogenous application of CRH mimics the maladaptive electrophysiological effects of CVMS by applying $300 \mathrm{~nm} \mathrm{CRH} \mathrm{directly} \mathrm{to} \mathrm{the} \mathrm{bath} \mathrm{solution.}$

Similar to CVMS, M-currents were significantly suppressed after CRH application $\left(F_{(1,14)}=15.299, p=0.002\right.$; and $p=0.023$, $0.049,0.011,0.004,0.001$, and 0.001 at $-50,-45,-40,-35$, -30 , and $-25 \mathrm{mV}$, respectively; Fig. $7 \mathrm{~L}$ ). At $-35 \mathrm{mV}$, M-current peak value was decreased from $143.34 \pm 14.50 \mathrm{pA}$ in Control slices $(n=8)$ to $52.92 \pm 14.85 \mathrm{pA}$ in $\mathrm{CRH}$-incubated slices $(n=$ $8 ; p=0.004)$. CRH application also significantly increased mEPSC amplitude relative to Control $(n=8$ per group; $p<0.01$; Fig. $7 M)$. However, CRH application did not alter mEPSC 
A
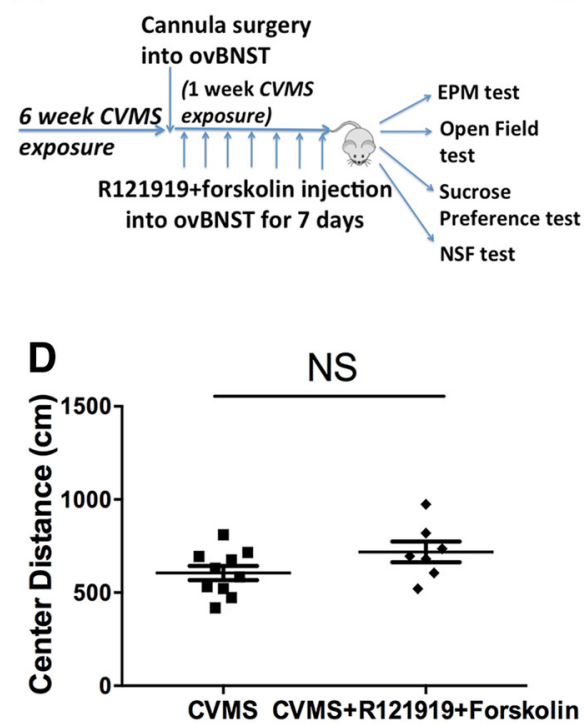

G
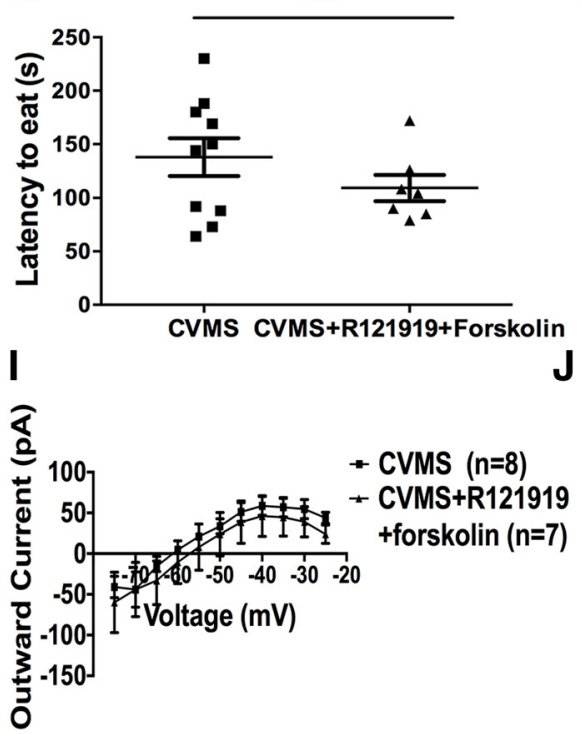

$\mathbf{L}$

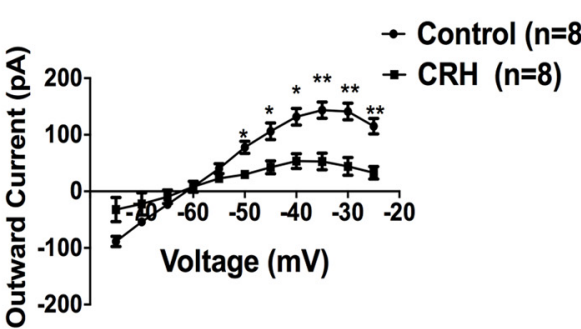

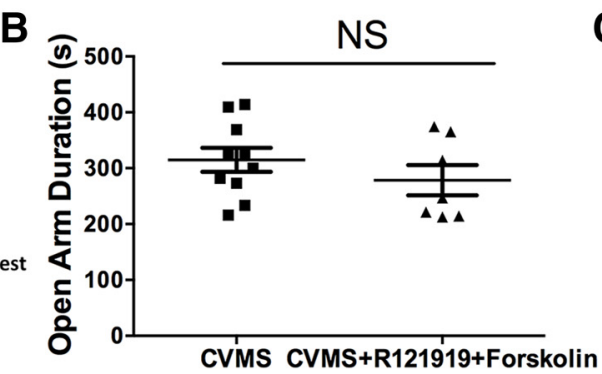

E
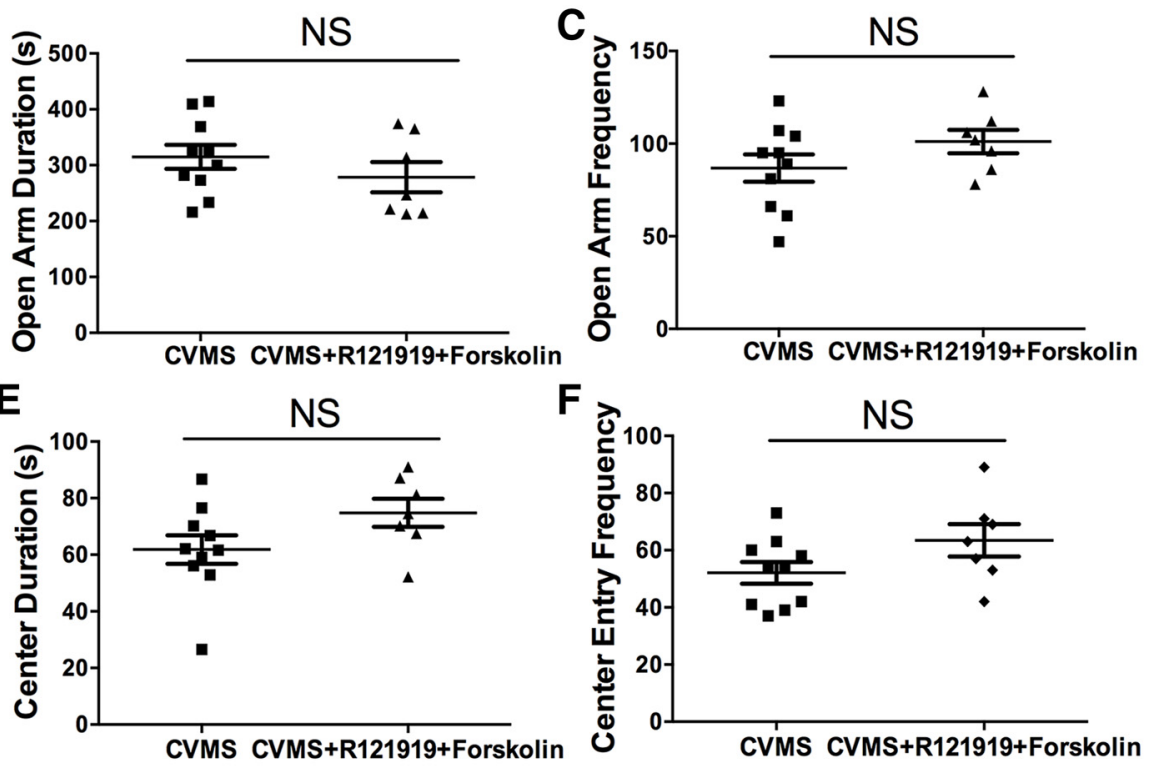

CVMS CVMS+R121919+Forskolin
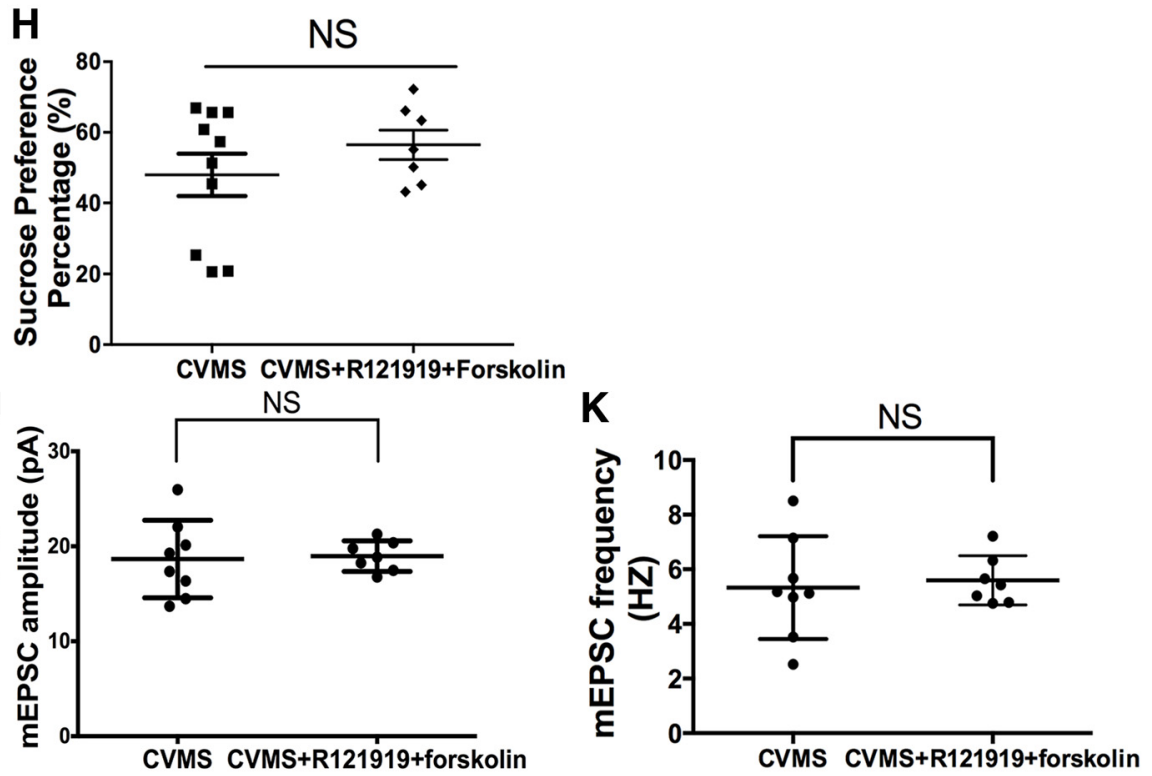

M

N
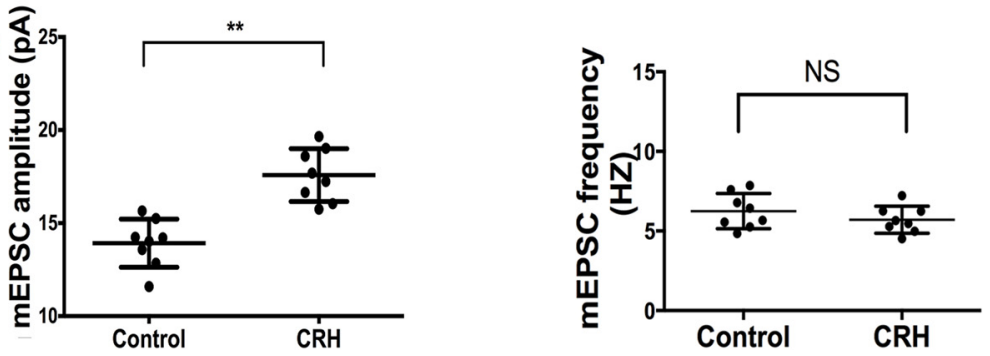

Figure 7. CVMS maladaptive effects on behavior and BNST electrophysiological parameters persist when CRHR1 is blocked and PKA is activated; bath application of CRH mimics CVMS effects on electrophysiological parameters of ovBNST CRH neurons. A, Schematics show that CRHR1-selective antagonist R121919 together with PKA-agonist forskolin was chronically infused into ovBNST of CVMS mice for a continuous $7 \mathrm{~d}$ through a cannula. Then maladaptive behaviors were compared (including EPM test, OF test, SPT test, and NSF test). CVMS exposure was continuously present during the 1 week chronic drug infusion period. B, Open arm duration time of the EPM from CVMS mice $(n=10)$ compared with R121919 + forskolin-treated CVMS mice $(n=7)$. C, Frequency that mice entries into open arm in the EPM after infusion of R121919 + forskolin into ovBNST in CVMS mice $(n=7)$ compared with saline infusion in CVMS mice $(n=10)$. D , Distance traveled in the middle of OF after infusion of R121919 + forskolin into ovBNST in CVMS mice $(n=7)$ compared with saline infusion in CVMS mice $(n=10)$. $\boldsymbol{E}$, Duration of time spent in the middle of OF test after infusion of R121919 + forskolin into ovBNST in CVMS mice $(n=7)$ compared with saline infusion in CVMS mice $(n=10)$. $\boldsymbol{F}$, Frequency of entries in 0F middle after infusion of R121919 + forskolin into ovBNST in CVMS mice $(n=7)$ compared with saline infusion in CVMS mice $(n=10)$. G, Latency to pellet consumption in the NSF test after infusion of R121919 + forskolin into ovBNST in CVMS mice $(n=7)$ compared with saline infusion in CVMS mice $(n=10)$. $\boldsymbol{H}$, Sucrose preference percentage after infusion of R121919 + forskolin into ovBNST in CVMS mice $(n=7)$ compared with saline infusion in CVMS mice $(n=10)$. $I$, Preincubation of the BNST slices from CVMS mice with $30 \mathrm{~min}$ R121919 + forskolin ( $n=7$ cells) on the M-current outward amplitude in the ovBNST CRH neurons compared with untreated neurons from CVMS mice ( $n=8$ cells). J, Preincubation of the BNST slices from CVMS mice with 30 min R121919 + forskolin ( $n=7$ cells) (Figure legend continues.) 
A

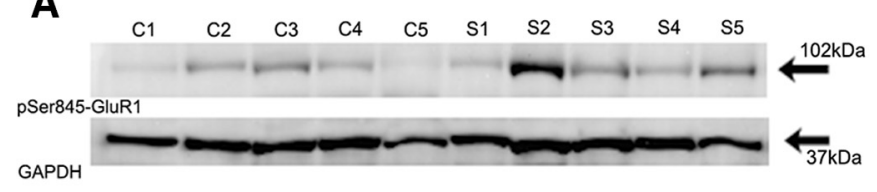

B

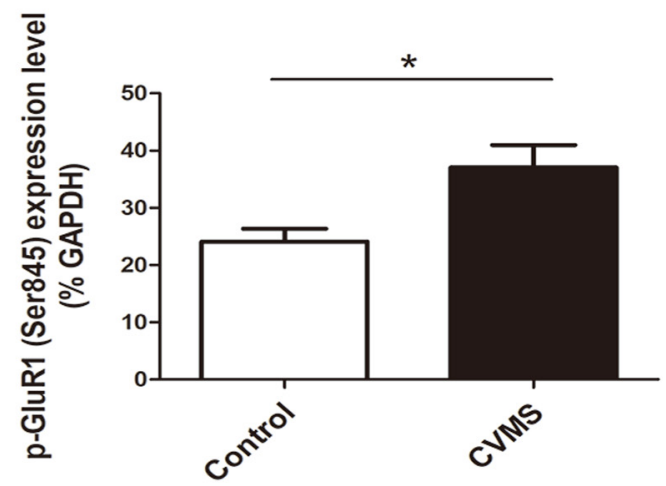

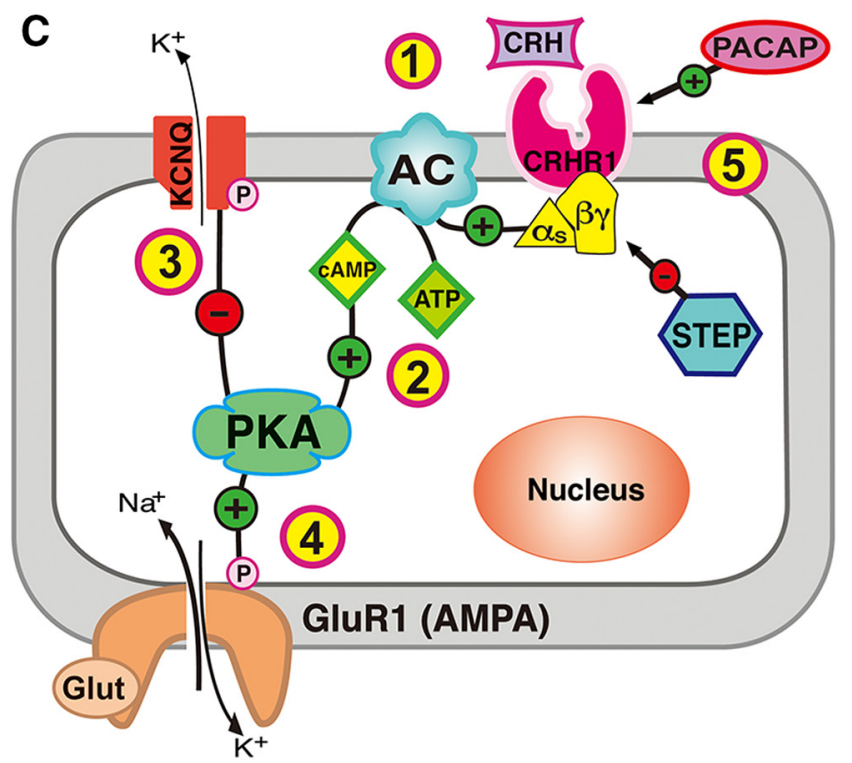

Figure 8. CVMS increases surface membrane expression of phosphorylated GluR1 subunit (p-GluR1 Ser845) in BNST. A, Comparison example of Western blot graph showing protein bands of pSer845-GluR1 ( $M W=102 \mathrm{kDa}$ ) in the BNST tissue of Control mice (lane 1-5; C1-C5) versus CVMS mice (lane 6-10; S1-S5). GAPDH (MW = $37 \mathrm{kDa}$ ) was used as the internal control. $\boldsymbol{B}$, Representative graph showing increased relative percent expression level of p-GluR1 (Ser845) in the BNST tissue from CVMS ( $n=5$ mice) versus Control ( $n=5$ mice) mice. C, A cellular model shows that chronic stress induces CRH production and release in the BNST, which sequentially activates CRHR1, a Gs-protein coupled membrane receptor. Then, (1) activation of G $\alpha$ s, which is linked to AC activation on the cell membrane (coupled to CRHR1), then generates cAMP production, which in turn (2) activates PKA enzyme. Activation of PKA then initiates two parallel phosphorylation pathways: (3) phosphorylates KCNQ channel on the cellular membrane to mediate inhibition of the M-current; and (4) phosphorylates GluR1 subunit of AMPAR at Ser845 (p-GluR1-S845) on the postsynaptic membrane and increases its surface expression to mediate potentiation of $\mathrm{mEPSC}$ amplitude. These two PKA-dependent pathways function to mediate suppression of $\mathrm{M}$-current and amplification of mEPSC amplitude, respectively. Meanwhile, (5) PACAP (functions as upstream stress regulator) and STEP (functions as CRH inhibitor) neuropeptides function to activate and inhibit CRH, respectively, in the CRH-associated stress signaling network. ${ }^{*} p<0.05$.

frequency $(p=0.287$; Fig. $7 N)$. Together, these data demonstrate that exogenous $\mathrm{CRH}$ application acutely suppresses $\mathrm{M}$-currents and increases mEPSC amplitude in ovBNST CRH neurons. These results mimic the effects of CVMS on ovBNST electrophysiology and indicate that CRH-mediated activation of CRHR1 and PKA are sufficient for mediating maladaptive effects of CVMS on BNST excitability.

\section{CVMS increases membrane surface expression of phosphorylated AMPAR GluR1 at Serine 845 (p-GluR1-Ser845) in mouse BNST}

PKA regulates membrane trafficking of the AMPAR GluR1 subunit via direct phosphorylation of the intracellular carboxy terminal motif at Serine 845 (S845) (Roche et al., 1996; Barria et al., 1997; Mammen et al., 1997). Since our results indicate that PKA is a downstream effector of CVMS in BNST, we next investigated whether CVMS increased surface expression of phosphorylated GluR1 at S845 in BNST. We used a brain slice surface biotinylation method to detect phosphorylation of GluR1 at S845 (Fig. $8 A$ ). Interestingly, surface expression of pS845-GluR1 was significantly increased in BNST tissue of CVMS mice relative to control $(p=0.028$; Fig. $8 B$ ). These data demonstrate that CVMS leads to

\section{$\leftarrow$}

(Figure legend continued.) on the mEPSC amplitude in the ovBNST CRH neurons compared with untreated neurons from CVMS mice ( $n=8$ cells). $\boldsymbol{K}$, Preincubation of the BNST slices from CVMS mice with 30 min R121919 + forskolin ( $n=7$ cells) on the mEPSC frequency in the ovBNST CRH neurons compared with untreated neurons from CVMS mice ( $n=8$ cells). $L, I-V$ plots of M-current after $300 \mathrm{~nm}$ CRH application ( $n=8$ cells) compared with Control $(n=8$ cells). $\boldsymbol{M}$, Average mEPSC amplitude after $300 \mathrm{~nm}$ (RH application ( $n=8$ cells) compared with Control ( $n=8$ cells). $\boldsymbol{N}$, Average mEPSC frequency after $300 \mathrm{~nm}$ CRH application ( $n=8$ cells) compared with Control ( $n=8$ cells). ${ }^{*} p<0.05,{ }^{* *} p<0.01$. NS, Not significantly different $(p>0.05)$. increased surface expression of phosphorylated GluR1 in BNST, which may underlie the CVMS-induced increase in mEPSC amplitude (Fig. 8C).

\section{Discussion}

BNST CRH signaling plays a pivotal role in stress-induced anxiety disorders (Choi et al., 2006; Tran et al., 2014; Butler et al., 2016; Donner et al., 2020). However, the precise mechanisms underlying how chronic stress induces BNST CRH neuronal dysfunction were unclear. CVMS is a widely used paradigm to elicit maladaptive behaviors in rodents (Choi et al., 2008), and to study neuroendocrine and neurophysiological effects of chronic stress (Willner, 2017). Our results reveal a novel PKA-dependent, CRHR1 receptor-mediated mechanism through which CVMS leads to persistent ovBNST CRH hyperactivation in male mice. When combined with the results showing increased CRH signaling, our data suggest that this $\mathrm{CRH}$-induced hyperactivation of ovBNST underlies chronic stress-induced maladaptive behaviors. Remarkably, local CRHR1 blockade or PKA inhibition in ovBNST reversed the electrophysiological and behavioral effects of CVMS.

Interestingly, we found that CVMS had a profound effect on M-currents, which are a subthreshold voltage-dependent, noninactivating outward $\mathrm{K}^{+}$current that stabilizes membrane potential and sets the cellular threshold for action potential firing (Yue and Yaari, 2004; Hernandez et al., 2008). Composed of Kv7 subunits (KCNQ) of the $\mathrm{K}^{+}$channel family (Delmas and Brown, 2005), M-channels function as a brake on repetitive action potential charges (Delmas and Brown, 2005) and play an essential role in controlling neuronal excitability (Robbins, 2001). Decreased M-currents allow neurons to fire more rapidly (Hernandez et al., 2008), as evidenced during XE991 (M-channel selective blocker) perfusion, suggesting significant hyperactivation. The 
delayed effect of XE991 application (robust firing bursts started after $\sim 6-7$ min; Fig. $2 J$ ) could be because KCNQ channel exhibits a delayed profile for channel activation and for the necessary membrane depolarization to accumulate. Diminished M-currents (Fig. $2 \mathrm{~K}$ ) are further accompanied by a more depolarized cellular resting membrane potential (Fig. $2 E$ ), indicating enhanced neuronal excitability. Consistent with these data, we found that handling led to an increased number of ovBNST c-fos ${ }^{+}$cells in mice exposed to CVMS, demonstrating increased activation in vivo (Fig. 2P). Since BNST links inputs from limbic forebrain structures to the hypothalamic and brainstem regions, this ovBNST c-fos activation may also be due to increased activation of upstream afferents. Future studies are required to focus on the circuitry effects of chronic stress.

Acute restraint stress suppresses $\mathrm{M}$-currents and increases cellular activity in paraventricular nucleus CRH neurons, which results in HPA hyperactivation (Zhou et al., 2017). However, there are very limited data assessing whether chronic stress also modulates M-currents in paraventricular nucleus or in BNST. Therefore, our study provides the direct cellular mechanism underlying how CVMS increases ovBNST neuronal excitability. Our qPCR results revealed no significant changes in KCNQ subunit mRNA expression after CVMS (data not shown), indicating that post-translational modifications (Marrion, 1997) likely account for M-current inhibition. Consistent with this hypothesis, we found that CVMS effects on M-currents are mediated by PKA activation (Fig. 6A). Additionally, we observed increased amplitude (but not frequency) of mEPSCs after CVMS (Fig. 2C,D), which suggests a postsynaptic effect. We then found that CVMS increased membrane surface expression of phosphorylated GluR1, which may underlie the effects on mEPSCs (O'Brien et al., 1998; Song and Huganir, 2002; Esteban et al., 2003; Thomas and Huganir, 2004; Man et al., 2007). Another possibility is that M-currents could modulate EPSCs. In cultured hippocampal neurons, the KCNQ blocker linopirdine reduces EPSC frequency (Zhou et al., 2011), and XE991 slice perfusion increases EPSC frequency in CA1 and auditory cortex pyramidal neurons (Lee and Kwag, 2012; Sun and Kapur, 2012). XE991 also diminishes the stimulation threshold for synaptic efficacy changes (FontánLozano et al., 2011; Shah et al., 2011). Thus, M-channels can directly affect EPSC properties and synaptic responses. Future experiments are necessary to determine the direct link between these two parameters. Importantly, CRH can directly result in increased glutamate release (Kash et al., 2008) and enhanced glutamatergic transmission in BNST (Fig. 7M). Therefore, endogenous engagement of CRH-mediated signaling also contributes to the CVMSinduced increase in mEPSC amplitude. Here we mainly assessed mEPSCs and M-currents (direct neurophysiological indexes of cellular excitability), but changes in other electrophysiological parameters, such as hyperpolarization-activated $\mathrm{H}$-currents or other intrinsic membrane conductance metrics, cannot be excluded.

$\mathrm{CRH}$ signaling is linked to negative affective states in BNST (Davis et al., 1997; Lee and Davis, 1997; Koob and Heinrichs, 1999; Sahuque et al., 2006; Butler et al., 2016; Faria et al., 2016). Notably, local CRH signaling in ovBNST (which harbors the highest CRH concentration in BNST) is stress responsive (Dabrowska et al., 2013). Consistently, increased CRH neuropeptide concentrations (Chappell et al., 1986; Stout et al., 2000) and mRNA levels (Kim et al., 2006; Hammack et al., 2009) are found in rat BNST after chronic stress. Interestingly, CVMS selectively increases CRHR1, but not CRHR2 mRNA expression (shown in Fig. 3R-S). Importantly, CRHR1 and CRHR2 subtypes play opposing roles in BNST during a stress response (de Kloet et al.,
2005; Joëls and Baram, 2009). Specifically, CRHR1 activation initiates the stress response (Sahuque et al., 2006; Tran et al., 2014), whereas CRHR2 activation facilitates stress recovery (Henckens et al., 2017). Therefore, increased CRHR1 expression in BNST may disrupt this balance, dampen stress-coping capability, and precipitate stress-related psychopathology. Our results showing that the infusion of the CRHR1-selective antagonist R121919 into ovBNST can reverse maladaptive behaviors (Fig. 4) is therefore consistent with several reports testing systemic effects of CRH modulators (Heinrichs et al., 2002; Gutman et al., 2003; Micioni Di Bonaventura et al., 2014; Dong et al., 2018).

We also assessed PACAP and STEP, which act as an upstream regulator and inhibitor of $\mathrm{CRH}$, respectively. PACAP is a key stress regulator (Hammack et al., 2010; Stroth et al., 2011) that stimulates CRH production and secretion (Agarwal et al., 2005). PACAP dysregulation is implicated in depression and PTSD in humans (Ressler et al., 2011). Chronic stress increases PACAP expression in the BNSTadl (Hammack et al., 2009), whereas PACAP infusion into the BNST increases plasma corticosterone concentrations (Lezak et al., 2014). The colocalization of PACAP-containing neurons and CRH-containing neurons in the ovBNST (data not shown) suggests that these two neuropeptides work in tandem to mediate stress response. STEP (a brainspecific tyrosine phosphatase; also known as protein tyrosine phosphatase nonreceptor type 5, PTPN5) plays a key role in stress resilience (Dabrowska et al., 2013; Karasawa and Lombroso, 2014) and functions to selectively buffer CRH neurons against overactivation after stress (Dabrowska et al., 2013). Importantly, $\mathrm{STEP}^{+}$neurons also colocalize with $\mathrm{CRH}^{+}$neurons in the ovBNST (data not shown), indicating a delicate local CRH signaling system. While CVMS upregulated expression of CRH and PACAP in the BNST, STEP expression was downregulated. These concomitant changes indicate a disrupted balance of $\mathrm{CRH}$ signaling in BNST and represent a novel stressinduced molecular signature.

CRHR1 activation stimulates Gs protein-coupled AC activity (Grammatopoulos, 2012), resulting in cAMP generation and activation of PKA in the BNST (Fig. 5D). PKA then phosphorylates both KCNQ channels and GluR1 AMPAR subunits, which mediates M-current inhibition (Marrion, 1997) (illustrated in Fig. $8 C$ ) and increased mEPSC amplitude (mediated by increased GluR1 surface expression) (Malinow and Malenka, 2002) (Fig. $8 C)$, respectively. In turn, these PKA-dependent cellular effects will result in stress-induced hyperactivation of BNST, HPA dysfunction, and maladaptive behaviors. Local ovBNST inhibition of PKA with H89 (Fig. 6) reversed the behavioral and electrophysiological effects of CVMS, demonstrating that ovBNST PKA activation is indispensable for CVMS effects. Therefore, we developed a model figure illustrating the signaling pathway of CRHR1. As depicted in Figure 8C, CVMS increases CRH levels in BNST, which results in CRHR1 activation and triggers the following: (1) activation of $\mathrm{G} \alpha \mathrm{s}$, which results in AC activation on cell membrane; (2) AC-dependent cAMP generation, which in turn activates PKA; (3) PKA-dependent phosphorylation of KCNQ channel membrane subunits, which inhibits M-currents; and (4) PKA also phosphorylates AMPAR GluR1 at Ser845 and increases GluR1 surface expression. In addition, PACAP and STEP function into this signaling to modulate CRH.

Importantly, BNST is a sexually dimorphic brain structure. In the human brain, the central nucleus of BNST is $40 \%$ larger in men (Zhou et al., 1995; Swaab et al., 2001; Chung et al., 2002), and a recent study (Uchida et al., 2019) also reported more $\mathrm{CRH}^{+}$neurons in both ovBNST and anterolateral BNST in fe- 
males than in males. While in this study we focused specifically on male mice, future studies using appropriate chronic stress paradigms for females (Harris et al., 2018; Yohn et al., 2019a,b) are necessary.

Until now, the precise mechanisms underlying how chronic stress induces BNST CRH neuronal dysfunction and mediates maladaptive behaviors were unknown. We demonstrated that CVMS increases CRH neuronal excitability by activating PKAdependent CRHR1 signaling in ovBNST, which in turn results in maladaptive behaviors. These electrophysiological and behavioral effects of CVMS were reversed by blocking CRHR1 or PKA in ovBNST. Our results highlight the critical role of BNST in the neural circuitry underlying stress-induced mood disorders. In addition, BNST CRH signaling also has an important role in reward-related disorders, such as drug or alcohol abuse (Lê et al., 2000; Francesconi et al., 2009; Silberman and Winder, 2013). Therefore, our results may also lead to a better mechanistic understanding of the role BNST CRH signaling plays in rewardrelated and stress-induced mood disorders.

\section{References}

Agarwal A, Halvorson LM, Legradi G (2005) Pituitary adenylate cyclaseactivating polypeptide (PACAP) mimics neuroendocrine and behavioral manifestations of stress: evidence for PKA-mediated expression of the corticotropin-releasing hormone (CRH) gene. Brain Res Mol Brain Res 138:45-57.

Barria A, Derkach V, Soderling T (1997) Identification of the $\mathrm{Ca}^{2+}$ / calmodulin-dependent protein kinase II regulatory phosphorylation site in the alpha-amino-3-hydroxyl-5-methyl-4-isoxazole-propionate-type glutamate receptor. J Biol Chem 272:32727-32730.

Butler RK, Oliver EM, Sharko AC, Parilla-Carrero J, Kaigler KF, Fadel JR, Wilson MA (2016) Activation of corticotropin releasing factorcontaining neurons in the rat central amygdala and bed nucleus of the stria terminalis following exposure to two different anxiogenic stressors. Behav Brain Res 304:92-101.

Chappell PB, Smith MA, Kilts CD, Bissette G, Ritchie J, Anderson C, Nemeroff CB (1986) Alterations in corticotropin-releasing factor-like immunoreactivity in discrete rat brain regions after acute and chronic stress. J Neurosci 6:2908-2914.

Chen C, Wilcoxen KM, Huang CQ, Xie YF, McCarthy JR, Webb TR, Zhu YF, Saunders J, Liu XJ, Chen TK, Bozigian H, Grigoriadis DE (2004) Design of 2,5-dimethyl-3-(6-dimethyl-4-methylpyridin-3-yl)-7-dipropylaminopyrazolo[1,5-a]py rimidine (NBI 30775/R121919) and structureactivity relationships of a series of potent and orally active corticotropinreleasing factor receptor antagonists. J Med Chem 47:4787-4798.

Ch'ng S, Fu J, Brown RM, McDougall SJ, Lawrence AJ (2018) The intersection of stress and reward: BNST modulation of aversive and appetitive states. Prog Neuropsychopharmacol Biol Psychiatry 87:108-125.

Choi DC, Nguyen MM, Tamashiro KL, Ma LY, Sakai RR, Herman JP (2006) Chronic social stress in the visible burrow system modulates stress-related gene expression in the bed nucleus of the stria terminalis. Physiol Behav 89:301-310.

Choi DC, Furay AR, Evanson NK, Ostrander MM, Ulrich-Lai YM, Herman JP (2007) Bed nucleus of the stria terminalis subregions differentially regulate hypothalamic-pituitary-adrenal axis activity: implications for the integration of limbic inputs. J Neurosci 27:2025-2034.

Choi DC, Evanson NK, Furay AR, Ulrich-Lai YM, Ostrander MM, Herman JP (2008) The anteroventral bed nucleus of the stria terminalis differentially regulates hypothalamic-pituitary-adrenocortical axis responses to acute and chronic stress. Endocrinology 149:818-826.

Chung WC, De Vries GJ, Swaab DF (2002) Sexual differentiation of the bed nucleus of the stria terminalis in humans may extend into adulthood. J Neurosci 22:1027-1033.

Clauss JA, Avery SN, Benningfield MM, Blackford JU (2019) Social anxiety is associated with BNST response to unpredictability. Depress Anxiety 36:666-675.

Cummings S, Elde R, Ells J, Lindall A (1983) Corticotropin-releasing factor immunoreactivity is widely distributed within the central nervous system of the rat: an immunohistochemical study. J Neurosci 3:1355-1368.
Dabrowska J, Hazra R, Guo JD, Dewitt S, Rainnie DG (2013) Central CRF neurons are not created equal: phenotypic differences in CRF-containing neurons of the rat paraventricular hypothalamus and the bed nucleus of the stria terminalis. Front Neurosci 7:156.

Daniel SE, Rainnie DG (2016) Stress modulation of opposing circuits in the bed nucleus of the stria terminalis. Neuropsychopharmacology 41: $103-125$.

Davis M, Walker DL, Lee Y (1997) Amygdala and bed nucleus of the stria terminalis: differential roles in fear and anxiety measured with the acoustic startle reflex. Philos Trans R Soc Lond B Biol Sci 352:1675-1687.

de Kloet ER, Joëls M, Holsboer F (2005) Stress and the brain: from adaptation to disease. Nat Rev Neurosci 6:463-475.

Delmas P, Brown DA (2005) Pathways modulating neural KCNQ/M (Kv7) potassium channels. Nat Rev Neurosci 6:850-862.

DeVos SL, Miller TM (2013) Direct intraventricular delivery of drugs to the rodent central nervous system. J Vis Exp 75:e50326.

Dong H, Keegan JM, Hong E, Gallardo C, Montalvo-Ortiz J, Wang B, Rice KC, Csernansky J (2018) Corticotrophin releasing factor receptor 1 antagonists prevent chronic stress-induced behavioral changes and synapse loss in aged rats. Psychoneuroendocrinology 90:92-101.

Donner NC, Davies SM, Fitz SD, Kienzle DM, Shekhar A, Lowry CA (2020) Crh receptor priming in the bed nucleus of the stria terminalis (BNST) induces tph2 gene expression in the dorsomedial dorsal raphe nucleus and chronic anxiety. Prog Neuropsychopharmacol Biol Psychiatry 96: 109730.

Esteban JA, Shi SH, Wilson C, Nuriya M, Huganir RL, Malinow R (2003) PKA phosphorylation of AMPA receptor subunits controls synaptic trafficking underlying plasticity. Nat Neurosci 6:136-143.

Faria MP, Miguel TT, Gomes KS, Nunes-de-Souza RL (2016) Anxiety-like responses induced by nitric oxide within the BNST in mice: role of CRF1 and NMDA receptors. Horm Behav 79:74-83.

Fontán-Lozano A, Suárez-Pereira I, Delgado-García JM, Carrión AM (2011) The M-current inhibitor XE991 decreases the stimulation threshold for long-term synaptic plasticity in healthy mice and in models of cognitive disease. Hippocampus 21:22-32.

Francesconi W, Berton F, Repunte-Canonigo V, Hagihara K, Thurbon D, Lekic D, Specio SE, Greenwell TN, Chen SA, Rice KC, Richardson HN, O’Dell LE, Zorrilla EP, Morales M, Koob GF, Sanna PP (2009) Protracted withdrawal from alcohol and drugs of abuse impairs long-term potentiation of intrinsic excitability in the juxtacapsular bed nucleus of the stria terminalis. J Neurosci 29:5389-5401.

Gabriel LR, Wu S, Melikian HE (2014) Brain slice biotinylation: an ex vivo approach to measure region-specific plasma membrane protein trafficking in adult neurons. J Vis Exp 86.

García-Moreno F, Pedraza M, Di Giovannantonio LG, Di Salvio M, LópezMascaraque L, Simeone A, De Carlos JA (2010) A neuronal migratory pathway crossing from diencephalon to telencephalon populates amygdala nuclei. Nat Neurosci 13:680-689.

Goode TD, Ressler RL, Acca GM, Miles OW, Maren S (2019) Bed nucleus of the stria terminalis regulates fear to unpredictable threat signals. Elife 8:e46525.

Grammatopoulos DK (2012) Insights into mechanisms of corticotropinreleasing hormone receptor signal transduction. Br J Pharmacol 166:8597.

Gungor NZ, Paré D (2016) Functional heterogeneity in the bed nucleus of the stria terminalis. J Neurosci 36:8038-8049.

Gutman DA, Owens MJ, Skelton KH, Thrivikraman KV, Nemeroff CB (2003) The corticotropin-releasing factor 1 receptor antagonist R121919 attenuates the behavioral and endocrine responses to stress. J Pharmacol Exp Ther 304:874-880.

Hammack SE, Richey KJ, Watkins LR, Maier SF (2004) Chemical lesion of the bed nucleus of the stria terminalis blocks the behavioral consequences of uncontrollable stress. Behav Neurosci 118:443-448.

Hammack SE, Cheung J, Rhodes KM, Schutz KC, Falls WA, Braas KM, May V (2009) Chronic stress increases pituitary adenylate cyclase-activating peptide (PACAP) and brain-derived neurotrophic factor (BDNF) mRNA expression in the bed nucleus of the stria terminalis (BNST): roles for PACAP in anxiety-like behavior. Psychoneuroendocrinology 34:833843.

Hammack SE, Roman CW, Lezak KR, Kocho-Shellenberg M, Grimmig B, Falls WA, Braas K, May V (2010) Roles for pituitary adenylate cyclaseactivating peptide (PACAP) expression and signaling in the bed nucleus 
of the stria terminalis (BNST) in mediating the behavioral consequences of chronic stress. J Mol Neurosci 42:327-340.

Harris AZ, Atsak P, Bretton ZH, Holt ES, Alam R, Morton MP, Abbas AI, Leonardo ED, Bolkan SS, Hen R, Gordon JA (2018) A novel method for chronic social defeat stress in female mice. Neuropsychopharmacology 43:1276-1283.

Heinrichs SC, De Souza EB, Schulteis G, Lapsansky JL, Grigoriadis DE (2002) Brain penetrance, receptor occupancy and antistress in vivo efficacy of a small molecule corticotropin releasing factor type I receptor selective antagonist. Neuropsychopharmacology 27:194-202.

Henckens MJ, Printz Y, Shamgar U, Dine J, Lebow M, Drori Y, Kuehne C, Kolarz A, Eder M, Deussing JM, Justice NJ, Yizhar O, Chen A (2017) CRF receptor type 2 neurons in the posterior bed nucleus of the stria terminalis critically contribute to stress recovery. Mol Psychiatry 22:1691-1700.

Herman JP, Cullinan WE (1997) Neurocircuitry of stress: central control of the hypothalamo-pituitary-adrenocortical axis. Trends Neurosci 20: $78-84$.

Herman MA, Varodayan FP, Oleata CS, Luu G, Kirson D, Heilig M, Ciccocioppo R, Roberto M (2016) Glutamatergic transmission in the central nucleus of the amygdala is selectively altered in Marchigian Sardinian alcohol-preferring rats: alcohol and CRF effects. Neuropharmacology 102:21-31.

Hernandez CC, Zaika O, Tolstykh GP, Shapiro MS (2008) Regulation of neural KCNQ channels: signalling pathways, structural motifs and functional implications. J Physiol 586:1811-1821.

Hu P, Liu J, Zhao J, Qi XR, Qi CC, Lucassen PJ, Zhou JN (2013) All-trans retinoic acid-induced hypothalamus-pituitary-adrenal hyperactivity involves glucocorticoid receptor dysregulation. Transl Psychiatry 3:e336.

Hu P, Liu J, Yasrebi A, Gotthardt JD, Bello NT, Pang ZP, Roepke TA (2016) Gq protein-coupled membrane-initiated estrogen signaling rapidly excites corticotropin-releasing hormone neurons in the hypothalamic paraventricular nucleus in female mice. Endocrinology 157:3604-3620.

Joëls M, Baram TZ (2009) The neuro-symphony of stress. Nat Rev Neurosci 10:459-466.

Ju G, Swanson LW (1989) Studies on the cellular architecture of the bed nuclei of the stria terminalis in the rat: I. Cytoarchitecture. J Comp Neurol 280:587-602.

Kageyama K, Suda T (2009) Regulatory mechanisms underlying corticotropin-releasing factor gene expression in the hypothalamus. Endocr J 56:335-344.

Karasawa T, Lombroso PJ (2014) Disruption of striatal-enriched protein tyrosine phosphatase (STEP) function in neuropsychiatric disorders. Neurosci Res 89:1-9.

Kash TL, Nobis WP, Matthews RT, Winder DG (2008) Dopamine enhances fast excitatory synaptic transmission in the extended amygdala by a CRFR1-dependent process. J Neurosci 28:13856-13865.

Kim SJ, Park SH, Choi SH, Moon BH, Lee KJ, Kang SW, Lee MS, Choi SH,Chun BG, Shin KH (2006) Effects of repeated tianeptine treatment on CRF mRNA expression in non-stressed and chronic mild stressexposed rats. Neuropharmacology 50:824-833.

Kim SY, Adhikari A, Lee SY, Marshel JH, Kim CK, Mallory CS, Lo M, Pak S, Mattis J, Lim BK, Malenka RC, Warden MR, Neve R, Tye KM, Deisseroth K (2013) Diverging neural pathways assemble a behavioural state from separable features in anxiety. Nature 496:219-223.

Koob GF, Heinrichs SC (1999) A role for corticotropin releasing factor and urocortin in behavioral responses to stressors. Brain Res 848:141-152.

Krawczyk M, Georges F, Sharma R, Mason X, Berthet A, Bézard E, Dumont EC (2011) Double-dissociation of the catecholaminergic modulation of synaptic transmission in the oval bed nucleus of the stria terminalis. J Neurophysiol 105:145-153.

Lê AD, Harding S, Juzytsch W, Watchus J, Shalev U, Shaham Y (2000) The role of corticotrophin-releasing factor in stress-induced relapse to alcohol-seeking behavior in rats. Psychopharmacology (Berl) 150:317324.

Lee S, Kwag J (2012) M-channels modulate the intrinsic excitability and synaptic responses of layer $2 / 3$ pyramidal neurons in auditory cortex. Biochem Biophys Res Commun 426:448-453.

Lee Y, Davis M (1997) Role of the hippocampus, the bed nucleus of the stria terminalis, and the amygdala in the excitatory effect of corticotropinreleasing hormone on the acoustic startle reflex. J Neurosci 17:64346446.
Lezak KR, Roelke E, Harris OM, Choi I, Edwards S, Gick N, Cocchiaro G, Missig G, Roman CW, Braas KM, Toufexis DJ, May V, Hammack SE (2014) Pituitary adenylate cyclase-activating polypeptide (PACAP) in the bed nucleus of the stria terminalis (BNST) increases corticosterone in male and female rats. Psychoneuroendocrinology 45:11-20.

Liu J, Conde K, Zhang P, Lilascharoen V, Xu Z, Lim BK, Seeley RJ, Zhu JJ, Scott MM, Pang ZP (2017) Enhanced AMPA receptor trafficking mediates the anorexigenic effect of endogenous glucagon-like peptide- 1 in the paraventricular hypothalamus. Neuron 96:897-909.e5.

Livak KJ, Schmittgen TD (2001) Analysis of relative gene expression data using real-time quantitative PCR and the 2(-delta delta $\mathrm{C}(\mathrm{T})$ ) method. Methods 25:402-408.

Lochner A, Moolman JA (2006) The many faces of H89: a review. Cardiovasc Drug Rev 24:261-274.

Lucassen PJ, Pruessner J, Sousa N, Almeida OF, Van Dam AM, Rajkowska G, Swaab DF, Czéh B (2014) Neuropathology of stress. Acta Neuropathol 127:109-135.

Malinow R, Malenka RC (2002) AMPA receptor trafficking and synaptic plasticity. Annu Rev Neurosci 25:103-126.

Mammen AL, Kameyama K, Roche KW, Huganir RL (1997) Phosphorylation of the alpha-amino-3-hydroxy-5-methylisoxazole-4-propionic acid receptor GluR1 subunit by calcium/calmodulin-dependent kinase II. J Biol Chem 272:32528-32533.

Man HY, Sekine-Aizawa Y, Huganir RL (2007) Regulation of $\alpha$-amino-3hydroxy-5-methyl-4-isoxazolepropionic acid receptor trafficking through PKA phosphorylation of the Glu receptor 1 subunit. Proc Natl Acad Sci U S A 104:3579-3584.

Marrion NV (1997) Control of M-current. Annu Rev Physiol 59:483-504.

Micioni Di Bonaventura MV, Ciccocioppo R, Romano A, Bossert JM, Rice KC, Ubaldi M, St Laurent R, Gaetani S, Massi M, Shaham Y, Cifani C (2014) Role of bed nucleus of the stria terminalis corticotrophinreleasing factor receptors in frustration stress-induced binge-like palatable food consumption in female rats with a history of food restriction. J Neurosci 34:11316-11324.

Morin SM, Ling N, Liu XJ, Kahl SD, Gehlert DR (1999) Differential distribution of urocortin- and corticotropin-releasing factor-like immunoreactivities in the rat brain. Neuroscience 92:281-291.

O’Brien RJ, Kamboj S, Ehlers MD, Rosen KR, Fischbach GD, Huganir RL (1998) Activity-dependent modulation of synaptic AMPA receptor accumulation. Neuron 21:1067-1078.

Pomrenze MB, Millan EZ, Hopf FW, Keiflin R, Maiya R, Blasio A, Dadgar J, Kharazia V, De Guglielmo G, Crawford E, Janak PH, George O, Rice KC, Messing RO (2015) A transgenic rat for investigating the anatomy and function of corticotrophin releasing factor circuits. Front Neurosci 9:487.

Pomrenze MB, Tovar-Diaz J, Blasio A, Maiya R, Giovanetti SM, Lei K, Morikawa H, Hopf FW, Messing RO (2019) A corticotropin releasing factor network in the extended amygdala for anxiety. J Neurosci 39:10301043

Qiu J, Bosch MA, Tobias SC, Grandy DK, Scanlan TS, Ronnekleiv OK, Kelly MJ (2003) Rapid signaling of estrogen in hypothalamic neurons involves a novel G-protein-coupled estrogen receptor that activates protein kinase C. J Neurosci 23:9529-9540.

Ressler KJ, Mercer KB, Bradley B, Jovanovic T, Mahan A, Kerley K, Norrholm SD, Kilaru V, Smith AK, Myers AJ, Ramirez M, Engel A, Hammack SE, Toufexis D, Braas KM, Binder EB, May V (2011) Post-traumatic stress disorder is associated with PACAP and the PAC1 receptor. Nature 470: 492-497.

Rivier C, Vale W (1983) Modulation of stress-induced ACTH release by corticotropin-releasing factor, catecholamines and vasopressin. Nature 305:325-327.

Robbins J (2001) KCNQ potassium channels: physiology, pathophysiology, and pharmacology. Pharmacol Ther 90:1-19.

Roche KW, O’Brien RJ, Mammen AL, Bernhardt J, Huganir RL (1996) Characterization of multiple phosphorylation sites on the AMPA receptor GluR1 subunit. Neuron 16:1179-1188.

Roepke TA, Qiu J, Smith AW, Rønnekleiv OK, Kelly MJ (2011) Fasting and 17beta-estradiol differentially modulate the M-current in neuropeptide $\mathrm{Y}$ neurons. J Neurosci 31:11825-11835.

Sahuque LL, Kullberg EF, McGeehan AJ, Kinder JR, Hicks MP, Blanton MG, Janak PH, Olive MF (2006) Anxiogenic and aversive effects of corticotropin-releasing factor (CRF) in the bed nucleus of the stria termi- 
nalis in the rat: role of CRF receptor subtypes. Psychopharmacology (Berl) 186:122-132.

Samuels BA, Anacker C, Hu A, Levinstein MR, Pickenhagen A, Tsetsenis T, Madroñal N, Donaldson ZR, Drew LJ, Dranovsky A, Gross CT, Tanaka KF, Hen R (2015) 5-HT1A receptors on mature dentate gyrus granule cells are critical for the antidepressant response. Nat Neurosci 18: $1606-1616$.

Samuels BA, Nautiyal KM, Kruegel AC, Levinstein MR, Magalong VM, Gassaway MM, Grinnell SG, Han J, Ansonoff MA, Pintar JE, Javitch JA, Sames D, Hen R (2017) The behavioral effects of the antidepressant tianeptine require the mu-opioid receptor. Neuropsychopharmacology 42:20522063.

Sanford CA, Soden ME, Baird MA, Miller SM, Schulkin J, Palmiter RD, Clark M, Zweifel LS (2017) A central amygdala CRF circuit facilitates learning about weak threats. Neuron 93:164-178.

Shah MM, Migliore M, Brown DA (2011) Differential effects of Kv7 (M-) channels on synaptic integration in distinct subcellular compartments of rat hippocampal pyramidal neurons. J Physiol 589:6029-6038.

Silberman Y, Winder DG (2013) Emerging role for corticotropin releasing factor signaling in the bed nucleus of the stria terminalis at the intersection of stress and reward. Front Psychiatry 4:42.

Silberman Y, Matthews RT, Winder DG (2013) A corticotropin releasing factor pathway for ethanol regulation of the ventral tegmental area in the bed nucleus of the stria terminalis. J Neurosci 33:950-960.

Sink KS, Walker DL, Freeman SM, Flandreau EI, Ressler KJ, Davis M (2013) Effects of continuously enhanced corticotropin releasing factor expression within the bed nucleus of the stria terminalis on conditioned and unconditioned anxiety. Mol Psychiatry 18:308-319.

Sokolova IV, Lester HA, Davidson N (2006) Postsynaptic mechanisms are essential for forskolin-induced potentiation of synaptic transmission. J Neurophysiol 95:2570-2579.

Song I, Huganir RL (2002) Regulation of AMPA receptors during synaptic plasticity. Trends Neurosci 25:578-588.

Sterrenburg L, Gaszner B, Boerrigter J, Santbergen L, Bramini M, Elliott E, Chen A, Peeters BW, Roubos EW, Kozicz T (2011) Chronic stress induces sex-specific alterations in methylation and expression of corticotropin-releasing factor gene in the rat. PLoS One 6:e28128.

Stout SC, Mortas P, Owens MJ, Nemeroff CB, Moreau J (2000) Increased corticotropin-releasing factor concentrations in the bed nucleus of the stria terminalis of anhedonic rats. Eur J Pharmacol 401:39-46.

Stroth N, Holighaus Y, Ait-Ali D, Eiden LE (2011) PACAP: a master regulator of neuroendocrine stress circuits and the cellular stress response. Ann N Y Acad Sci 1220:49-59.

Sun J, Kapur J (2012) M-type potassium channels modulate Schaffer collateral-CA1 glutamatergic synaptic transmission. J Physiol 590: 3953-3964.

Surget A, Saxe M, Leman S, Ibarguen-Vargas Y, Chalon S, Griebel G, Hen R, Belzung C (2008) Drug-dependent requirement of hippocampal neurogenesis in a model of depression and of antidepressant reversal. Biol Psychiatry 64:293-301.

Swaab DF, Chung WC, Kruijver FP, Hofman MA, Ishunina TA (2001)
Structural and functional sex differences in the human hypothalamus. Horm Behav 40:93-98.

Thomas GM, Huganir RL (2004) MAPK cascade signalling and synaptic plasticity. Nat Rev Neurosci 5:173-183.

Tran L, Schulkin J, Greenwood-Van Meerveld B (2014) Importance of CRF receptor-mediated mechanisms of the bed nucleus of the stria terminalis in the processing of anxiety and pain. Neuropsychopharmacology 39:2633-2645.

Uchida K, Otsuka H, Morishita M, Tsukahara S, Sato T, Sakimura K, Itoi K (2019) Female-biased sexual dimorphism of corticotropin-releasing factor neurons in the bed nucleus of the stria terminalis. Biol Sex Differ 10:6.

Vranjkovic O, Gasser PJ, Gerndt CH, Baker DA, Mantsch JR (2014) Stressinduced cocaine seeking requires a beta- 2 adrenergic receptor-regulated pathway from the ventral bed nucleus of the stria terminalis that regulates CRF actions in the ventral tegmental area. J Neurosci 34:12504-12514.

Walker DL, Toufexis DJ, Davis M (2003) Role of the bed nucleus of the stria terminalis versus the amygdala in fear, stress, and anxiety. Eur J Pharmacol 463:199-216.

Walker DL, Miles LA, Davis M (2009) Selective participation of the bed nucleus of the stria terminalis and CRF in sustained anxiety-like versus phasic fear-like responses. Prog Neuropsychopharmacol Biol Psychiatry 33:1291-1308.

Wang HS, McKinnon D (1995) Potassium currents in rat prevertebral and paravertebral sympathetic neurones: control of firing properties. J Physiol 485:319-335.

Wei F, Qiu CS, Kim SJ, Muglia L, Maas JW, Pineda VV, Xu HM, Chen ZF, Storm DR, Muglia LJ, Zhuo M (2002) Genetic elimination of behavioral sensitization in mice lacking calmodulin-stimulated adenylyl cyclases. Neuron 36:713-726.

Willner P (2017) The chronic mild stress (CMS) model of depression: history, evaluation and usage. Neurobiol Stress 6:78-93.

Yi F, Liu SS, Luo F, Zhang XH, Li BM (2013) Signaling mechanism underlying alpha2A-adrenergic suppression of excitatory synaptic transmission in the medial prefrontal cortex of rats. Eur J Neurosci 38:2364-2373.

Yohn CN, Ashamalla SA, Bokka L, Gergues MM, Garino A, Samuels BA (2019a) Social instability is an effective chronic stress paradigm for both male and female mice. Neuropharmacology 160:107780.

Yohn CN, Dieterich A, Bazer AS, Maita I, Giedraitis M, Samuels BA (2019b) Chronic non-discriminatory social defeat is an effective chronic stress paradigm for both male and female mice. Neuropsychopharmacology 44:2220-2229.

Yue C, Yaari Y (2004) KCNQ/M channels control spike afterdepolarization and burst generation in hippocampal neurons. J Neurosci 24:4614-4624.

Zhou JJ, Gao Y, Kosten TA, Zhao Z, Li DP (2017) Acute stress diminishes $\mathrm{M}$-current contributing to elevated activity of hypothalamic-pituitaryadrenal axis. Neuropharmacology 114:67-76.

Zhou JN, Hofman MA, Gooren LJ, Swaab DF (1995) A sex difference in the human brain and its relation to transsexuality. Nature 378:68-70.

Zhou X, Song M, Chen D, Wei L, Yu SP (2011) Potential role of KCNQ/Mchannels in regulating neuronal differentiation in mouse hippocampal and embryonic stem cell-derived neuronal cultures. Exp Neurol 229:471483. 